\title{
SAFETY ASSESSMENT OF EUROCODE 3 STABILITY DESIGN RULES FOR THE FLEXURAL BUCKLING OF COLUMNS
}

\author{
Luís Simões da Silva, Trayana Tankova*, Liliana Marques and Carlos Rebelo \\ ISISE, Department of Civil Engineering, University of Coimbra, Coimbra, Portugal \\ Polo II, Pinhal de Marrocos \\ 3030-290 Coimbra, PORTUGAL \\ *(Corresponding author: E-mail: ttankova@uc.pt)
}

Received: 25 September 2015; Accepted: 21 October 2015

\begin{abstract}
This paper presents the safety assessment of Eurocode 3 - part 1-1 [1] rules for the flexural buckling columns using hot-rolled cross-sections (I and H cross-sections).

The safety assessment follows the procedure presented in Annex D of EN 1990 [2]. It is based on a large number (7332) of numerical simulations (GMNIA) covering various relevant parameters.

Firstly, it is concluded that the level of safety is consistent across the various types of I and $\mathrm{H}$ cross-sections and steel grades (maximum variation of 6.3\%) except for S460 and minor axis buckling. It is therefore proposed to adjust the buckling curves for minor axis buckling for S460.

Secondly, the magnitude of the partial factor $\gamma_{\mathrm{M} 1}$ is assessed. It is shown that depending on the random variables included in the analysis (just yield stress $\mathrm{f}_{\mathrm{y}}$; yield stress $\mathrm{f}_{\mathrm{y}}$ and cross-section geometry; or yield stress $\mathrm{f}_{\mathrm{y}}$, cross-section geometry and modulus of elasticity E) the average value of $\gamma_{\mathrm{M} 1}$ varies from 0.941 to 1.049 with c.o.v varying from $4.3 \%$ to $6.3 \%$.
\end{abstract}

Keywords: Column, flexural buckling, safety assessment, design rules, steel, Eurocode 3, stability

DOI:10.18057/IJASC.2016.12.3.7

\section{INTRODUCTION}

A main purpose of modern design codes is to provide design principles and application rules that lead to appropriate safety levels. The safety margin reflects the risk society is willing to accept yet that maximises economical design. Nowadays, it is possible to link quantitatively a specific design rule and the corresponding failure probability [3]. However, because design codes combine a very large number of design rules that evolved over many decades of expensive research work and their semi-probabilistic implementation was only effectively started in the 1990's [4], the safety level is not uniform across the various design rules and also within single design rules. Eurocodes 3 , part 1-1 [1] is no exception, despite the enormous work that was put in its development and the wide past proven experience that it incorporates. In this paper focus is given to the stability verification of columns.

The design verification of the flexural buckling resistance of columns in Eurocode 3 is based on the buckling curve approach and the underlying European buckling curves that were established in the 1970's. Their development was based on an extensive experimental programme carried out by the European Convention for Constructional Steelwork (ECCS) in several European countries [5]. The theoretical background was summarized by Beer and Schulz [6] by thorough analysis of the experimental programme presented in Sfintesco [5], assessing various imperfections that can possibly occur and affect the resistance of compressed members. Furthermore, the safety of one of the curves was evaluated by Monte Carlo simulation accounting for the variability of various parameters [7]. Finally, Maquoi and Rondal [8] derived the analytical Ayrton-Perry format of the design verification and the curves were put into equation.

Recently, within the scope of the stability rules for steel members, it was recognized that the 
extensions, corrections and improvements that evolved over a long period of time since the establishment of the column buckling curves, coupled with the development of new structural steels with largely improved mechanical and geometrical properties and dramatically improved quality control procedures, required a reassessment of the current safety levels of the stability design rules of EC3-1-1 [1]. Thus, this paper addresses a systematic assessment of the safety levels of the fundamental case of flexural buckling of I-shaped hot-rolled steel columns. Firstly, the adopted assumptions for the safety assessment are summarized. A parametric study for the evaluation of rules for flexural buckling of prismatic columns in EC3-1-1 is subsequently carried out. It covers several slenderness ranges, level of residual stresses, yield stress, and cross-section shapes, such that a thorough evaluation of the several members covered by the analysed stability design rules is possible, using advanced nonlinear numerical simulations. Finally, a discussion on the value of the partial factor $\gamma_{\mathrm{M} 1}$ to be adopted based on the obtained results is proposed, leading to the proposal of adjustments to the buckling curves.

\section{SAFETY ASSESSMENT OF STABILITY DESIGN RULES}

\subsection{Scope and Assumptions}

The assessment encompasses the design rules for flexural buckling of columns given in EC3-1-1, given in clause 6.3.1 for hot-rolled sections. The partial factor $\gamma_{\mathrm{M} 1}$ is obtained based on the methodology given in Annex D of EN 1990. Following [2] the procedure is briefly summarized in Section 2.2. The buckling strength of the members is obtained using advanced numerical finite element simulations (GMNIA). Numerical models are detailed in Section 2.4.

For each case (in plane and out-of-plane buckling), a wide range of I-shaped cross sections covering several buckling curves are analysed across practical ranges of slenderness. The parametric study is organized by buckling mode and it is defined in Section 3.1 for the flexural buckling of columns.

In the safety assessment of the design rules carried out in Section 3, the following assumptions are considered:

- The variability of the input variables in the design model is not considered for the calculation of $V_{\delta}$; the value is obtained from nominal properties since the "experimental" results are considered with nominal properties;

- The coefficient of variation of the basic variables, $V_{r t}$, considers only the variability of cross section dimensions, yield stress and modulus of elasticity; for these parameters more information is known and documented with recent data. The adopted distributions are summarized in Section 2.3.

\subsection{Basis of Design}

The framework for the statistical assessment of the steel members was presented and discussed in Tankova et al. [9]. The procedure proposed in Annex D of EN 1990 is summarized in Figure 1: 
Step 1: Resistance function

$$
r_{t}=g_{r t}\left(X_{1}, X_{2} \ldots X_{n}\right)
$$

Step 2: Compare experimental and theoretical values

Step 3: Estimate mean vale of correction factor $b$

$$
b=\sum_{i=1}^{n} r_{e, i} r_{t, i} / \sum_{i=1}^{n} r_{t, i}^{2}
$$

Step 4: Estimate CoV of the error:

$$
\begin{gathered}
\delta_{i}=r_{e, i} / b r_{t, i} \quad \Delta_{\mathrm{i}}=\ln \left(\delta_{\mathrm{i}}\right) \\
{s_{\Delta}}^{2}=\frac{1}{n-1} \sum_{i=1}^{n}\left(\Delta_{i}-\bar{\Delta}\right)^{2} \\
V_{\delta}=\sqrt{\exp \left({s_{\Delta}}^{2}\right)-1}
\end{gathered}
$$

Step 5: Analyze compatibility - if the resistance function is acceptable

\section{Figure 1. Flow Chart - Annex D}

Step 6: Determine c.o.v $V_{r t, i}$ of the basic variables

Step 7: Determine design value of the resistance

$$
\begin{gathered}
Q_{\delta}=\sqrt{\ln \left(V_{\delta}^{2}+1\right)} \quad Q_{r t}=\sqrt{\ln \left(V_{r t}^{2}+1\right)} \\
Q=\sqrt{\ln \left(V_{\delta}^{2}+V_{r t}{ }^{2}+1\right)} \\
r_{d}=\left[\begin{array}{ll}
\left.b g_{r t} \underline{\left(X_{m}\right.}\right) \exp \left(-k_{d, \infty} \frac{Q_{r t}{ }^{2}}{Q}-k_{d, n} \frac{Q_{\delta}{ }^{2}}{Q}-0.5 Q^{2}\right) & n \leq 30 \\
b g_{r t}\left(\underline{X_{m}}\right) \exp \left(-k_{d, \infty} Q-0.5 Q^{2}\right) & n \rightarrow \infty
\end{array}\right.
\end{gathered}
$$

In Step 6, $V_{r t}$ shall be determined as follows:

$$
V_{r t}^{2}=\frac{1}{g_{r t} \underline{\left(X_{m}\right)^{2}}} \sum_{j=1}^{k}\left(\frac{\partial g_{r t}\left(X_{j}\right)}{\partial X_{j}} \sigma_{j}\right)^{2}
$$

The partial derivatives are computed numerically using expression (2) adopting a sufficiently small increment " $\Delta \mathrm{X}_{\mathrm{i}}$ " for each test specimen separately, leading to $\gamma_{\mathrm{M}, \mathrm{i}}$ for each specimen; finally the mean value for the subset is considered.

$$
\frac{\partial r_{t}}{\partial X_{i}} \approx \frac{r_{t}\left(X_{1}, \ldots, X_{i}+\Delta X_{i}, \ldots . X_{j}\right)-r_{t}\left(X_{1}, \ldots, X_{i}, \ldots . X_{j}\right)}{\Delta X_{i}}
$$

\subsection{Adopted Distributions}

In Step 6 of the procedure given in Figure 1, information about the scatter of the basic input parameters is required. The distributions summarized in Table 1 were considered as a reference for the variability of the yield stress. The data was obtained from (Simões da Silva et al. 2009) [10] for S235 and S355; and from OPUS [11] for S460, for which there was sufficient number of coupon tests to give reliable distributions (see Annex A for further detail).

The parametric study given in Section 3.1 was defined in order to cover various parameters. Regarding the material properties, a well-known phenomenon is the variation of yield stress with thickness; hence, in this assessment, the provisions of EN 10025[12] have been adopted. Since there was not sufficient information about the distributions of the material properties with the thickness variation, the distributions from Table 1 were extrapolated from the nominal yield stress for $\mathrm{t}_{\mathrm{f}} \leq 16 \mathrm{~mm}$ and the coefficient of variation was kept constant.

Table 1. Adopted Reference Yield Stress Distributions

\begin{tabular}{|c|c|c|c|c|}
\hline \multirow{2}{*}{ Steel } & $\mathbf{f}_{\mathbf{y}, \mathbf{n o m}}$ & $\mathbf{f}_{\mathbf{y}, \mathbf{m}}$ & $\mathbf{c . o . v}$ & Source \\
\cline { 2 - 5 } $\mathbf{M p a}$ & $\mathrm{MPa}$ & - & - \\
\hline \hline $\mathbf{S 2 3 5}$ & 235 & 297.3 & $5.8 \%$ & $\begin{array}{c}\text { Silva et al } \\
{[10]}\end{array}$ \\
\hline $\mathbf{S 3 5 5}$ & 355 & 419.4 & $4.8 \%$ & $\begin{array}{c}\text { Silva et al } \\
{[10]}\end{array}$ \\
\hline $\mathbf{S 4 6 0}$ & 460 & 520.0 & $5.2 \%$ & OPUS [11] \\
\hline
\end{tabular}


It is noted that the extrapolated distributions were then considered for computation of the $\gamma_{\mathrm{Mi}}$ value of each column, according to its cross-section flange thickness irrespective of whether EN 10025 or EC3-1-1 were used for the choice of nominal yield stress.

Regarding cross-section geometrical properties, statistical indicators from Alpsten [13] and results reported in Taras [14] were adopted for H or I sections and are given in Table 2:

Table 2. Adopted Geometrical Distributions

\begin{tabular}{|c|c|c|c|}
\hline & Mean & c.o.v & Source \\
\hline \hline $\mathbf{b}_{\mathbf{m}} / \mathbf{b}_{\text {nom }}$ & 1 & $0.9 \%$ & \multirow{2}{*}{$\begin{array}{c}\text { Alpsten, G. (1972) } \\
{[13],}\end{array}$} \\
\cline { 1 - 2 } $\mathbf{h}_{\mathbf{m}} / \mathbf{h}_{\text {nom }}$ & 1 & $0.9 \%$ & $\begin{array}{c}\text { Taras A. (2010) } \\
{[14]}\end{array}$ \\
\cline { 1 - 2 } $\mathbf{t}_{\mathbf{f m}} / \mathbf{t}_{\text {fnom }}$ & 0.975 & $3.0 \%$ & \\
\cline { 1 - 2 } $\mathbf{t}_{\mathbf{w m}} / \mathbf{t}_{\mathbf{w n o m}}$ & 1.025 & $4.0 \%$ & \multicolumn{2}{|c}{} \\
\hline
\end{tabular}

$b_{m}$ denotes the mean value of the flange width, $b_{\text {nom }}$ denotes the nominal value of the flange width, $h_{m}$ is the mean value of the cross-section height, $h_{n o m}$ is the nominal value of the cross-section height, $t_{f}$ is the mean value of the flange thickness, $t_{f, n o m}$ denotes the nominal value of the flange thickness, $t_{w}$ denotes the mean value of the web thickness and $t_{w, n o m}$ denotes the nominal value of the web thickness. Although the reports by Alpsten [13] and Taras [14] are not recent, the statistical characterization of the cross-section dimensions is in line with the statistical indicators for area, moment of inertia and bending modulus as given in the report from the research project PROQUA [15], see Table 3. Considering a normal distribution, the computation of the distributions of area and moment of inertia from the distributions of the cross-section dimensions from Table 2 leads to values of mean and standard deviation that fall within the range of Table 3 . Hence, the statistical description of the cross-section dimensions of Table 2 are adopted in the calculation as input random variables.

Table 3. Statistical Distributions for Geometry (A, W, I) PROQUA [15]

\begin{tabular}{|c|c|c|}
\hline & Mean, $\mathbf{X}_{\mathbf{m}}$ & $\boldsymbol{\sigma}_{\mathbf{x}}$ \\
\hline$A, W, I$ PROQUA $[15]$ & $0.99 \mathrm{X}_{\mathrm{nom}}$ & $0.01-0.04 \mathrm{X}_{\mathrm{m}}$ \\
\hline
\end{tabular}

A distribution for the modulus of elasticity is adopted based on recommendations given in DNV [16] that reports $\mathrm{E}_{\mathrm{m}}=\mathrm{E}_{\text {nom }}$ and a c.o.v. of $5 \%$. It is noted that the statistical characterization of the modulus of elasticity is not so strongly supported by experimental evidence. Furthermore, the testing procedures are not often as reliable with respect to this property. Hence, in Section 3 a sensitivity study is carried out with respect to this property by also considering a c.o.v. of $3 \%$.

\section{$2.4 \quad$ Numerical Modelling}

Advanced finite element simulations were carried out to obtain "experimental" results. In this "experimental" programme, finite element software product Abaqus 6.12 [17] was used. Each column is modelled with four-node linear shell elements (S4) with six degrees of freedom.

Advanced analyses were performed using geometrical and material nonlinearities with imperfections, also known as GMNIA. This type of analysis allows capturing the second order effects which are essential for stability problems. 
Material nonlinearity is incorporated in the model by using elastic-plastic constitutive law with strain hardening, according to Figure 2, following the recommendations from ECCS [18].

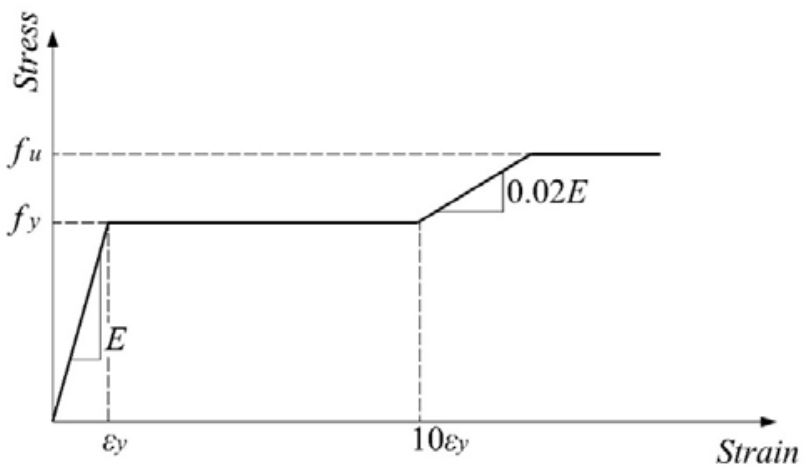

Figure 2, Constitutive Law

The yield stress, $f_{y}$, is considered either according to the provisions of the product standard EN 10025 [12], or from Table 3.1 of EC3-1-1. Since Table 3.1 of EC3-1-1 does not account for $t>80$ $\mathrm{mm}$, for such cases, the same value of $f_{y}$ as in EN 10025 was considered, see Figure 3.

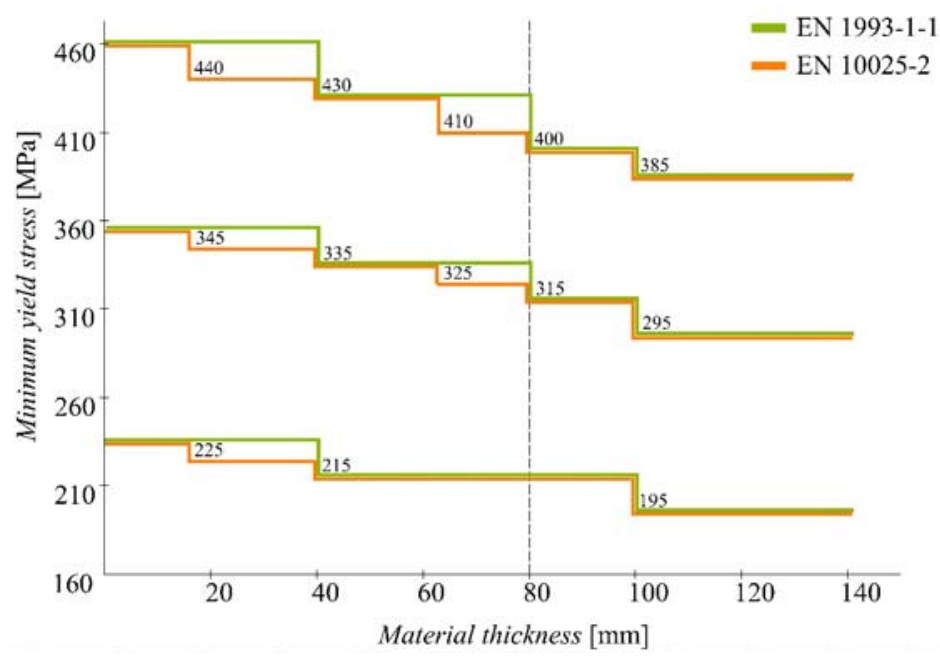

Figure 3. Variation of the Yield Stress with Thickness

Geometrical imperfections were modelled using an initial sinusoidal imperfection introduced in the weak or strong axis of the cross-section, with an amplitude $e_{0}=L / 1000$ at mid span. Residual stresses were considered according to Figure 4 . The adopted value of $f_{y} *$ indicated in Figure 4 was $f_{y, 235}=235 \mathrm{MPa}$. Nevertheless, for comparison, equivalent cases were included using the nominal value of the yield stress $f_{y}$.

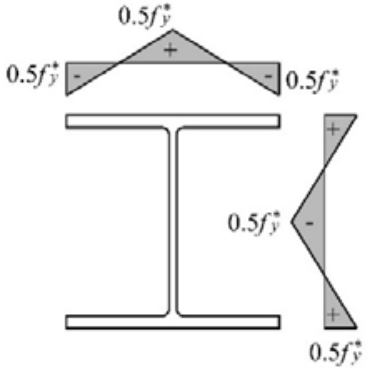

(a) Hot-rolled, $h / b<1.2$

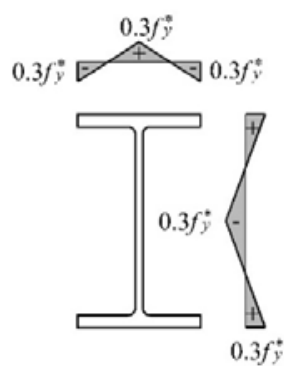

(b) Hot-rolled, $h / b>1.2$

Figure 4. Residual Stresses ("+"” Tension and "-_Compression) 
The load is applied using load stepping routine, in which the increment size is chosen in order to meet the accuracy and convergence criteria. The equilibrium equations are solved for each increment using Newton-Raphson iteration technique. The adopted mesh comprises 16 sub-divisions in the web and flanges and 100 divisions along the member's axis per $10 \mathrm{~m}$ length.

The boundary conditions are implemented as end fork conditions in the shell model. The following restraints are used - vertical $(\delta z)$ and transverse $(\delta y)$ displacements and rotation about the xx-axis $(\phi x)$ are prevented at the supports. In addition, the longitudinal displacement $(\delta x)$ is prevented in one end. End cross-sections are constrained to remain straight. Whenever major axis buckling behaviour is to be studied, minor axis displacements are restrained at the tip of both flanges and centre of the web.

\section{FLEXURAL BUCKLING OF PRISMATIC COLUMNS}

As the main purpose of this study is the assessment of existing rules for flexural buckling of prismatic columns from EC3-1-1, in order to cover all types of hot-rolled sections according to Table 6.2 of EC3-1-1, a wide range of I-shaped cross-sections was selected so that flange thickness and the ratio $h / b$ would vary.

In this section, firstly, the scope of the parametric study is introduced; subsequently, the methodology for assessment of results is given and finally, the results are discussed.

\subsection{Parametric Study: Definition}

Table 4 illustrates the hot-rolled section selected for the study, organized according to Table 6.2 of EC3-1-1. The selection includes 2 (two) American profiles.

Table 4. Sections of the Parametric Study for Columns

\begin{tabular}{|c|c|c|c|c|c|}
\hline \multirow[b]{2}{*}{ Fabrication } & \multirow{2}{*}{\multicolumn{2}{|c|}{ Limits }} & \multicolumn{3}{|c|}{ Sections } \\
\hline & & & $\mathbf{h} / \mathbf{b}$ & $\begin{array}{c}\boldsymbol{t}_{\boldsymbol{f}} \\
{[\mathrm{mm}]}\end{array}$ & Profiles \\
\hline \multirow{13}{*}{ Rolled } & \multirow{13}{*}{$\mathrm{h} / \mathrm{b}>1.2$} & \multirow{13}{*}{$t_{\mathrm{f}} \leq 40 \mathrm{~mm}$} & 1.22 & 40 & HEM340 \\
\hline & & & 1.3 & 19 & HEA400 \\
\hline & & & 1.7 & 40 & HEM500 \\
\hline & & & 1.92 & 6.9 & IPE140 \\
\hline & & & 2.19 & 40 & HEM650 \\
\hline & & & 1.74 & 5.2 & IPE80 \\
\hline & & & 1.82 & 5.7 & IPE100 \\
\hline & & & 1.33 & 24 & HEB400 \\
\hline & & & 1.67 & 28 & HEB500 \\
\hline & & & 1.95 & 7.4 & IPE160 \\
\hline & & & 1.41 & 40 & HEM400 \\
\hline & & & 1.50 & 24 & HEB450 \\
\hline & & & 1.28 & 40 & HEM360 \\
\hline
\end{tabular}


Table 4. Sections of the Parametric Study for Columns (Continued)

\begin{tabular}{|c|c|c|c|c|c|}
\hline \multirow[t]{2}{*}{ Fabrication } & \multirow{2}{*}{\multicolumn{2}{|c|}{ Limits }} & \multicolumn{3}{|c|}{ Sections } \\
\hline & & & $\mathbf{h} / \mathbf{b}$ & $\begin{array}{c}\boldsymbol{t}_{\boldsymbol{f}} \\
{[\mathrm{mm}]}\end{array}$ & Profiles \\
\hline \multirow{35}{*}{ Rolled } & \multirow{21}{*}{$\mathbf{h} / \mathbf{b}>1.2$} & \multirow{13}{*}{$40 \mathrm{~mm}<\mathrm{t}_{\mathrm{f}} \leq 100 \mathrm{~mm}$} & 2.28 & 55.9 & HL920x588 \\
\hline & & & 2.29 & 62 & HL920x656 \\
\hline & & & 2.35 & 99.1 & HL920x1077* \\
\hline & & & 3.36 & 64 & HE1000x584 \\
\hline & & & 2.31 & 73.9 & HL920x787 \\
\hline & & & 2.30 & 68.1 & HL920x725 \\
\hline & & & 3.08 & 65 & W920x310x576 \\
\hline & & & 2.56 & 70 & HL1000x748 \\
\hline & & & 2.05 & 69.1 & W610x325x551 \\
\hline & & & 2.06 & 54 & HE600x399 \\
\hline & & & 2.36 & 46 & HE700x352 \\
\hline & & & 2.69 & 54 & HE800x444 \\
\hline & & & 3.01 & 54 & HE900x466 \\
\hline & & \multirow{8}{*}{$t_{\mathrm{f}}>100 \mathrm{~mm}$} & 1.231 & 130 & HD400x1202* \\
\hline & & & 2.4 & 109 & HL920x1194* \\
\hline & & & 1.201 & 106 & HD400x900 \\
\hline & & & 1.23 & 115 & HD400x990 \\
\hline & & & 2.37 & 115.1 & HL920x1269* \\
\hline & & & 2.31 & 115.1 & HL920x1377* \\
\hline & & & 1.25 & 125 & HD400x1086 \\
\hline & & & 1.26 & 140 & HD400x1299 \\
\hline & \multirow{14}{*}{$\mathbf{h} / \mathbf{b} \leq 1.2$} & \multirow{13}{*}{$t_{1} \leq 100 \mathrm{~mm}$} & 1.2 & 22.5 & HEB360 \\
\hline & & & 1.17 & 97 & HD400x818 \\
\hline & & & 0.96 & 8 & HEA100 \\
\hline & & & 1.0 & 19 & HEB300 \\
\hline & & & 1.1 & 39 & HEM300 \\
\hline & & & 1.0 & 10 & HEB100 \\
\hline & & & 1.0 & 15 & HEB200 \\
\hline & & & 1.17 & 17.5 & HE360A \\
\hline & & & 1.09 & 67.6 & HD400x551 \\
\hline & & & 1.12 & 77.1 & HD400x634 \\
\hline & & & 1.04 & 52.6 & HD400x421 \\
\hline & & & 1.10 & 72.30 & HD400x592 \\
\hline & & & 1.00 & 17 & HEB240 \\
\hline & & $t_{f}>100 \mathrm{~mm}$ & \multicolumn{3}{|c|}{ No sections exist } \\
\hline
\end{tabular}

*Heavy sections

The parametric study comprised 7332 numerical models, both for minor and major axis flexural buckling behaviour (3666 models for each mode). It includes several levels of slenderness, different steel grades, and two different levels of residual stresses, as given in Table 5. 
Table 5. Parametric Study for Columns: Additional Parameters

\begin{tabular}{|c|c|c|c|}
\hline Fabrication & $\bar{\lambda}$ & $\begin{array}{c}\text { Material and } \\
\text { standard for } \\
\boldsymbol{f}_{\boldsymbol{y}}\end{array}$ & $\begin{array}{c}\text { Material } \\
\text { imperfections }\end{array}$ \\
\hline \hline & & & $\mathbf{h} \leq \mathbf{b} \mathbf{2 :}$ \\
& $0.5 ; 0.6 ; 0.7 ;$ & $\mathbf{E N ~ 1 0 0 2 5 :}$ & $f_{y, 235}$ \\
& 0.8 & & $f_{y}$ \\
Rolled & $0.9 ; 1.0 ; 1.2 ;$ & $\mathrm{S} 235$ & $\mathbf{h} / \mathbf{b}>\mathbf{1 . 2 :}$ \\
& $1.4 ; 1.5$ & $\mathrm{~S} 355$ & $f_{y, 235}$ \\
& $1.6 ; 1.8 ; 2.0 ;$ & $\mathrm{S} 460$ & $f_{y}$ \\
& 2.5 & & \\
\hline
\end{tabular}

For the evaluation of the flexural buckling resistance of steel columns, clause 6.3.1 in EC3-1-1 is considered to represent the theoretical result, $\mathrm{r}_{\mathrm{t} i}$, in the safety assessment procedure. The design procedure is summarized in Table 6 for simply supported members of length L, whereas the imperfection factors are summarized in Table 7 for the cross section shapes covered by the parametric study. The latter imperfection factors are considered from Table 6.1 and 6.2 of EC3-1-1 and from (Snijder et al. [19], [20]) for hot-rolled heavy cross-sections with t $>100 \mathrm{~mm}$ and $\mathrm{h} / \mathrm{b}>1.2$.

Table 6. Verification of Flexural Buckling of Columns, about Minor Axis $(\mathrm{i}=\mathrm{z})$ and Major Axis $(\mathrm{i}=\mathrm{y})$

\begin{tabular}{|c|c|}
\hline Parameter & Expression \\
\hline$N_{R k}$ & $\begin{array}{c}A \cdot f_{y}-\text { class } 1,2 \text { and } 3 \text { cross sections } \\
A_{\text {eff }} . f_{y}-\text { class } 4 \text { cross sections }\end{array}$ \\
\hline$N_{c r, z}$ or $N_{c r, y}$ & $N_{c r, i}=\frac{\pi^{2} E I_{i}}{L^{2}}$ \\
\hline $\bar{\lambda}_{i}$ & $\overline{\boldsymbol{\lambda}}_{i}=\sqrt{N_{R k} / N_{C R, i}}$ \\
\hline$\alpha_{i}$ & See Table 7 \\
\hline$\eta_{i}$ & $\alpha_{i}\left(\bar{\lambda}_{i}-0.2\right)$ \\
\hline$\phi_{i}$ & $0.5 \times\left(1+\eta_{i}+\bar{\lambda}_{i}^{2}\right)$ \\
\hline$\chi_{i}$ & $1 /\left(\phi_{i}+\sqrt{\phi_{i}^{2}-\bar{\lambda}_{i}^{2}}\right) \leq 1$ \\
\hline Verification & $N_{E d} \leq N_{b, i, R d}=\chi_{i} \times N_{R k} / \gamma_{M 1}$ \\
\hline
\end{tabular}

Additionally, for $\bar{\lambda}_{i} \leq 0.2$ and $\frac{N_{E d}}{N_{c r, i}} \leq 0.04$, flexural buckling about axis $i$ does not need to be verified and only cross sectional checks apply $\left(\chi_{i}=1\right)$.

In Section 3.3 and Section 3.4 the partial factors $\gamma_{M 1}$ for several subsets are obtained respectively for minor and major axes flexural buckling. Selected input variables for safety assessment and subsets are described in the corresponding sub-sections. 
Table 7. Imperfection Factors and Generalized Imperfection Limits for Flexural Buckling

\section{2}

\begin{tabular}{|c|c|c|c|c|c|c|c|}
\hline \multirow[b]{3}{*}{ Fabrication } & & & \multirow[b]{3}{*}{ Axis } & \multicolumn{4}{|c|}{ Source } \\
\hline & \multirow{2}{*}{\multicolumn{2}{|c|}{ Limits }} & & \multicolumn{2}{|c|}{ EC3-1-1 } & \multicolumn{2}{|c|}{ (Cajot et al. (2013)) } \\
\hline & & & & $\begin{array}{l}\text { S235 } \\
\text { S355 }\end{array}$ & S460 & $\begin{array}{l}\text { S235 } \\
\text { S355 }\end{array}$ & S460 \\
\hline \multirow{5}{*}{ Rolled } & \multirow{3}{*}{$\begin{array}{l}\stackrel{N}{\Lambda} \\
\hat{\Omega}\end{array}$} & $\mathrm{t} f \leq 40 \mathrm{~mm}$ & $\begin{array}{l}y-y \\
z-z\end{array}$ & $\begin{array}{l}0.21 \\
0.34\end{array}$ & $\begin{array}{l}0.13 \\
0.13\end{array}$ & - & - \\
\hline & & $\begin{array}{c}40 \mathrm{~mm}<\mathrm{t}_{\mathrm{f}} \leq 100 \\
\mathrm{~mm}\end{array}$ & $\begin{array}{l}y-y \\
z-z\end{array}$ & $\begin{array}{l}0.34 \\
0.49 \\
\end{array}$ & $\begin{array}{l}0.21 \\
0.21 \\
\end{array}$ & - & - \\
\hline & & $\mathrm{tt}_{\mathrm{f}}>100 \mathrm{~mm}$ & $\begin{array}{l}y-y \\
z-z\end{array}$ & - & - & $\begin{array}{l}0.34 \\
0.49\end{array}$ & $\begin{array}{l}0.21 \\
0.34\end{array}$ \\
\hline & \multirow{2}{*}{ 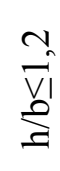 } & $\mathrm{t}_{\mathrm{f}} \leq 100 \mathrm{~mm}$ & $\begin{array}{l}y-y \\
z-z\end{array}$ & $\begin{array}{l}0.34 \\
0.49\end{array}$ & $\begin{array}{l}0.21 \\
0.21\end{array}$ & - & - \\
\hline & & $\mathrm{t}_{\mathrm{f}}>100 \mathrm{~mm}$ & $\begin{array}{l}y-y \\
z-z\end{array}$ & $\begin{array}{l}0.76 \\
0.76\end{array}$ & $\begin{array}{l}0.49 \\
0.49\end{array}$ & - & - \\
\hline
\end{tabular}

Parametric Study: Methodology

In the subsequent sections the results for minor and major axis flexural bucking of columns are detailed. The following main topics are discussed:

- Influence of the specification of the minimum yield stress according to EN 10025 and Eurocode 3;

- Influence of the magnitude of residual stresses used in the numerical analyses;

- Influence of imperfection factor $\alpha$ for steel grade S460;

- Validation of the buckling curves for heavy sections;

- Influence of the number of random variables;

Throughout the following paragraphs, charts and tables, the following methodology is adopted:

- The partial factors for different subsets are computed considering the Annex D procedure summarized in Section 2.2.

- The assessment is performed using normalized values of the partial factor. The normalization is done with respect to the average value of $\gamma_{\mathrm{M} 1}$ obtained for $\underline{S 235 \text { and } S 355, t_{f} \leq 40 \mathrm{~mm}, \mathrm{~h} / \mathrm{b}>1.2}$ and major axis of flexural buckling, considering the yield stress $f_{y}$ as the only random variable.

- Whenever a subset according to slenderness is analysed, the following division is adopted:

- Low slenderness - normalized slenderness $\bar{\lambda} \in[0.5 ; 0.8]$;

- $\quad$ Medium slenderness- normalized slenderness $\bar{\lambda} \in(0.8 ; 1.5]$;

- High slenderness - normalized slenderness $\bar{\lambda} \in(1.5 ; 2.5]$;

- For the first 4 topics listed above, only the variability of the yield stress is considered, as a relative assessment is sufficient to establish the influence of each parameter;

- In order to establish the influence of additional random variables, the following variables are considered: yield stress, geometrical dimensions of the cross-section and modulus of elasticity.

\subsection{Results and Discussion - Minor axis Flexural Buckling}

Hereby the results for minor axis flexural buckling are presented and discussed. Firstly, the reference cases for hot-rolled cross sections are analysed: the value of the yield stress both in $r_{e}$ and $r_{t}$ is considered according to EN 10025 and the level of the residual stresses is proportional to

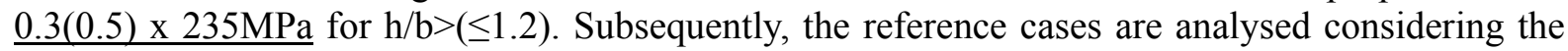
value of the yield stress and $r_{t}$ according to Table 3.1 of EC3-1-1, the experimental value $r_{e}$ is 
computed according to the EN 10025, assuming it as the "reality". Finally, the reference cases are analysed considering the level of the residual stresses proportional to $\underline{0.3(0.5) \times f_{y}}$ for $\mathrm{h} / \mathrm{b}>(\leq 1.2)$; More detailed results may be found in Table B1 and Table B2 of Annex B.

\subsubsection{Results for hot-rolled cross sections}

In the following all results are normalized (see Section 3.2). Partial factors are evaluated using the procedure from Annex D, as summarized in Section 2.2 and considering the variability of the yield stress only.

The parametric study was constructed aiming to cover all buckling curves for hot-rolled $\mathrm{H}$ and I sections and therefore, the sample includes members whose resistance is evaluated using different imperfection factors ( $\alpha$ according to Table 7), different steel grades which are defined by different distributions, etc. Hence, further division into subsets is required, in order to avoid undesired bias of the results.

Since the reduction factor is mainly a function of slenderness, results should be assessed and organized by subsets of the slenderness ranges, as shown in Figure 5. The subsets are adopted according to Section 3.2: Low [0.5; 0.8]; Medium $(0.8 ; 1.5]$; and High $(1.5 ; 2.5]$. A larger partial factor is observed for S460 in Figure 5 when compared to the other steel grades for all slenderness ranges. A possible explanation for this value is that the imperfection factors currently adopted for steel grade S460 may not be appropriate. This was independently confirmed by Lindner [21] and may thus require adjustment.

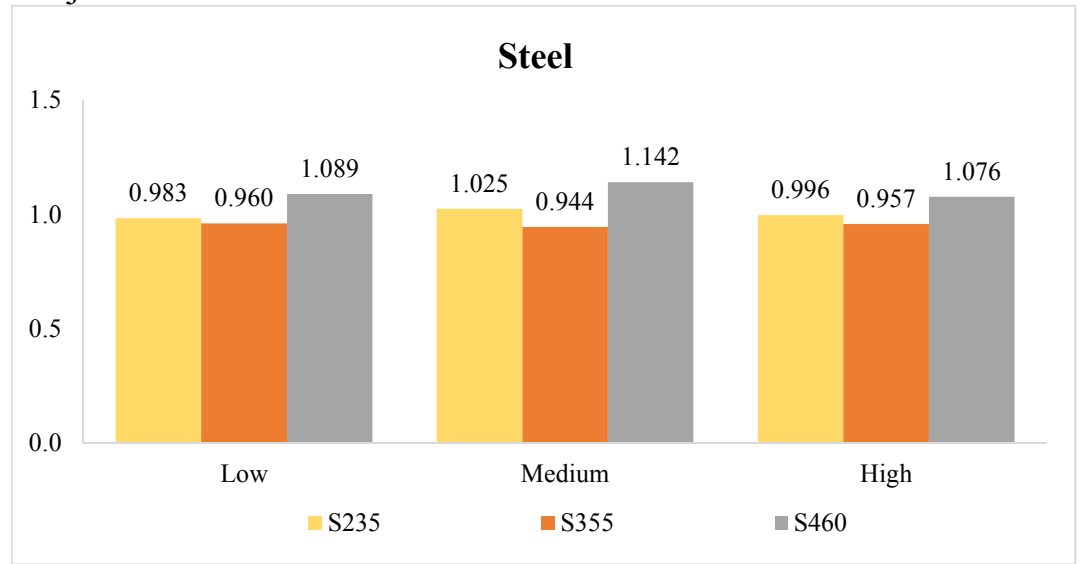

Figure 5. All Results Organized by Slenderness for Hot-rolled Cross Sections $-\mathrm{f}_{\mathrm{y}}$ according to EN 10025 (Table B1, Annex B)

Figure 6 illustrates the results organized by the divisions given in Table 7, regardless of the slenderness range, thus allowing a direct comparison of the buckling curves in EC3-1-1. Firstly, it is clear that steel grade S355 leads to lower values of $\gamma_{\mathrm{M} 1}$. This is due to the relative amplitude of the residual stress with respect to the yield stress of the member when compared to S235 steel. Figure 6 again confirms that the imperfection factors for S460 may not be adequate, except for $\mathrm{h} / \mathrm{b}>1.2, \mathrm{tr}>100 \mathrm{~mm}$ because they were recently proposed and calibrated as this range was not available in the code (Snijder et al. [19], [20]). Finally, note that no cases with $h / b \leq 1.2$ and $\mathrm{t}_{\mathrm{f}}>100 \mathrm{~mm}$ are included in the parametric study since no sections with these characteristics were found in catalogues. 


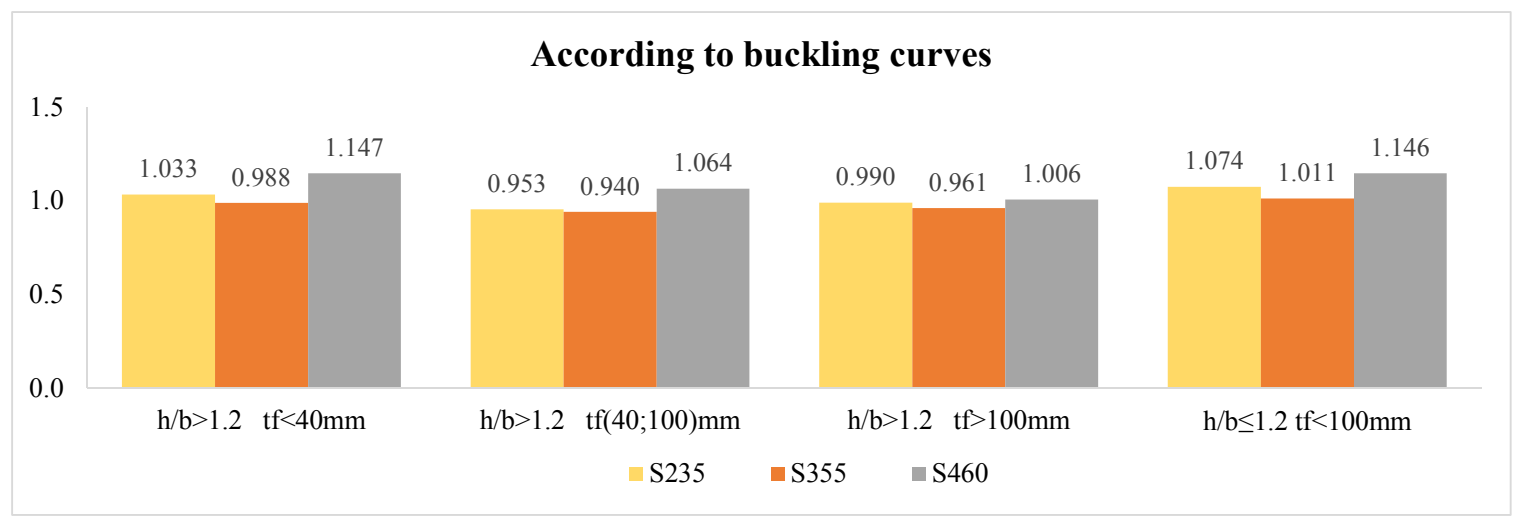

Figure 6. All Results organized by Buckling Curve Division for Hot-rolled

Cross sections - $\mathrm{f}_{\mathrm{y}}$ according to EN 10025 (Table B1, Annex B)

Additional subsets were considered for $h / b \leq 1.2$. The results are presented in Figure 7 , the same trends being observed.

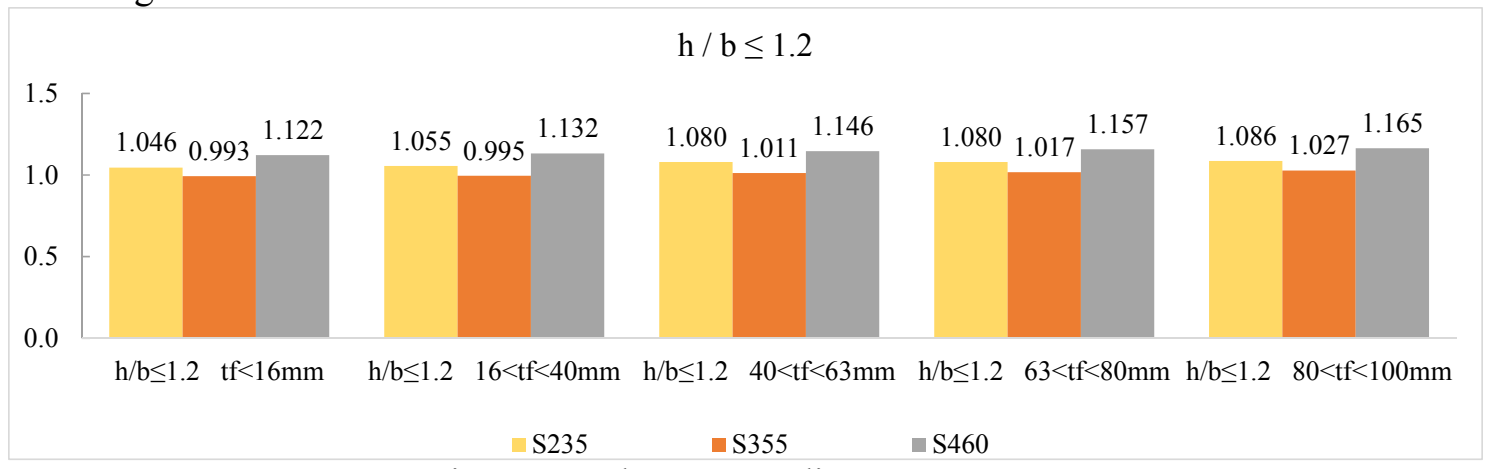

Figure 7. Subsets according to EN10025

\subsubsection{Influence of the variation of the yield stress with thickness}

The value of the yield stress in the theoretical value of the resistance $r_{t}$ is now considered according to EC3-1-1, Table 3.1 and the "experimental" resistance $r_{e}$ is computed considering the sub-divisions according to EN 10025, and presented in relative terms with respect to the results of EN 10025 (Figure 8). Results of Figure 8 are better interpreted together with Figure 3.

The second group for S235 and third group give the same values since the specifications of the yield stress in EN 10025 and EC3-1-1 are equal for the cross sections considered in the parametric study. On the other hand, for the first and fourth groups as well as second group for S355 and S460, differences are noted, for sections with thicknesses falling in the ranges $(16 ; 40)$ and $(63 ; 80)$, since the specifications in EC3-1-1 and EN 10025 are different in those ranges.

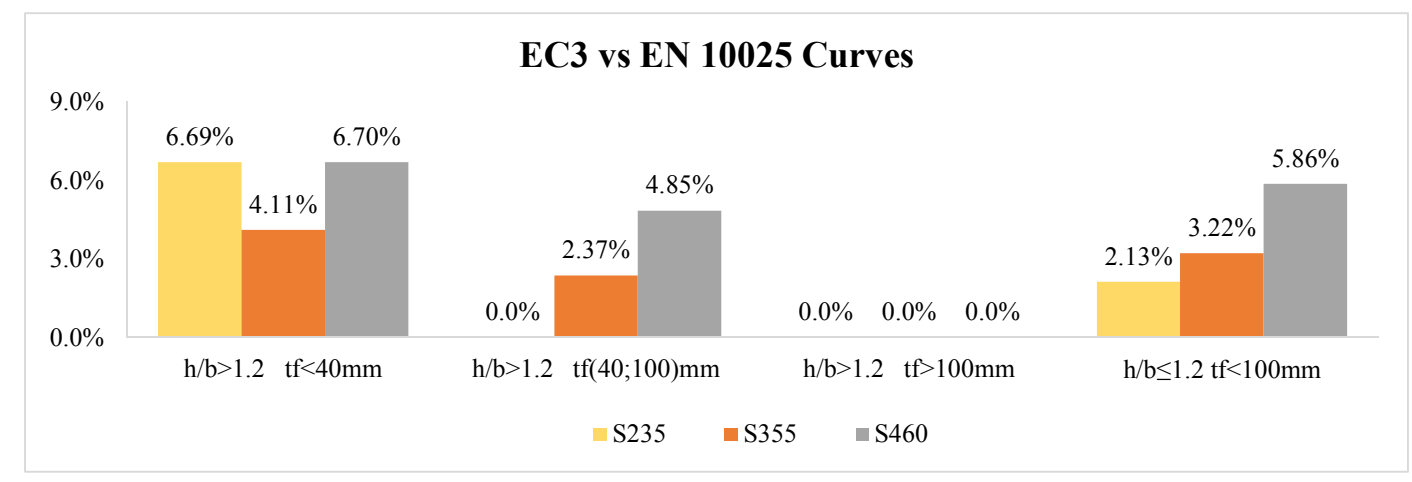


Figure 8. Percentage Difference for Normalized $\gamma_{\mathrm{M} 1}$ between Yield Stress Calculated according to EC3-1-1 and EN 10025

The results in Figure 8 include thickness ranges that are different from the division according to EN 10025; hence, Figure 9 compares results between EN 10025 and EC3-1-1 for the intervals defined in EN 10025, highlighting maximum differences of about $8 \%$.

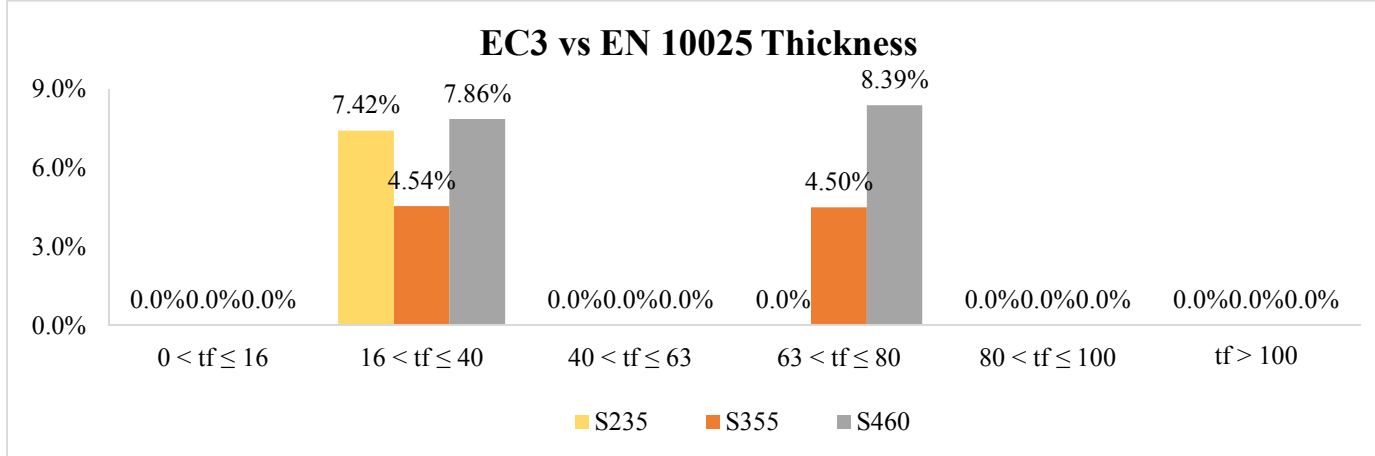

Figure 9. Percentage Difference for Normalized $\gamma_{\mathrm{M} 1}$ between Yield Stress Calculated according to EC3-1-1 and EN 10025

\subsubsection{Influence of the assumptions for the residual stress}

Figure 10 and Figure 11 present relative results for the partial factor similarly to Figure 6 , but assuming the conservative option that the level of the residual stresses is proportional to the yield

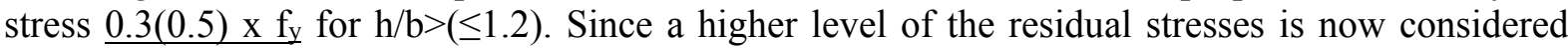
(more conservative), the partial factor is expected to increase. This is observed both for steels S355 and S460, see Figure 10 and Figure 11 respectively. For steel grade S235, the analysis is not relevant.

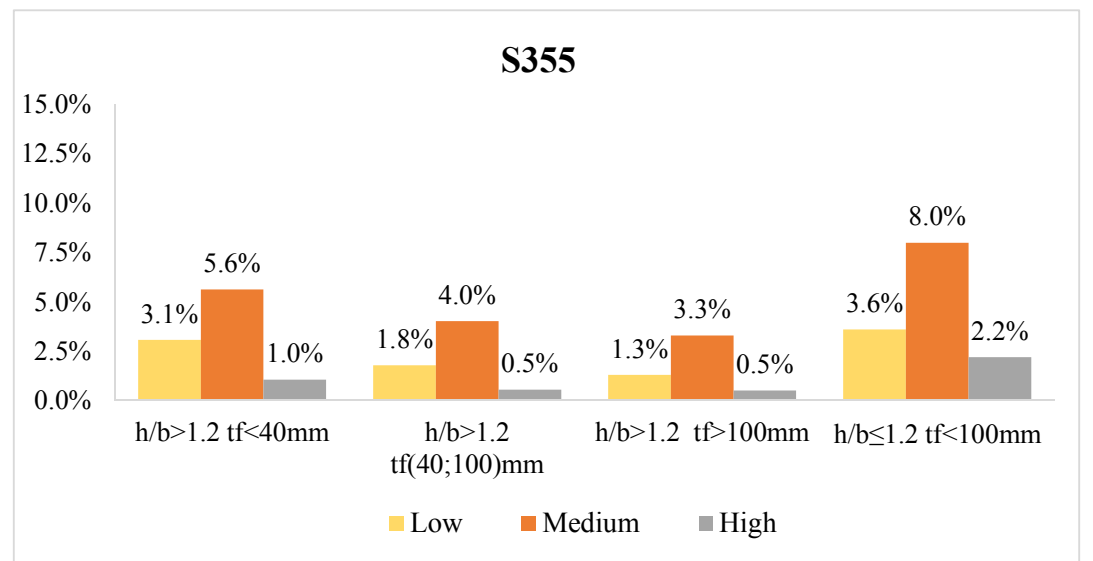

Figure 10. All Results organized by Buckling Curve and Slenderness Division for Hot-rolled Cross Sections and Steel Grade S355 - Residual Stress Proportional to the Actual Value of $f_{y}\left(f_{y}\right.$ according to EN 10025)

Figure 10 and Figure 11 represent the subsets by buckling curve, slenderness and steel grade. It is clearly seen that the influence of the residual stresses has higher impact in the medium slenderness range, as expected. Moreover, Figure 11 further shows that the adoption of residual stresses proportional to the yield stress $\underline{0.3(0.5) \times f_{y}}$ is too conservative. 


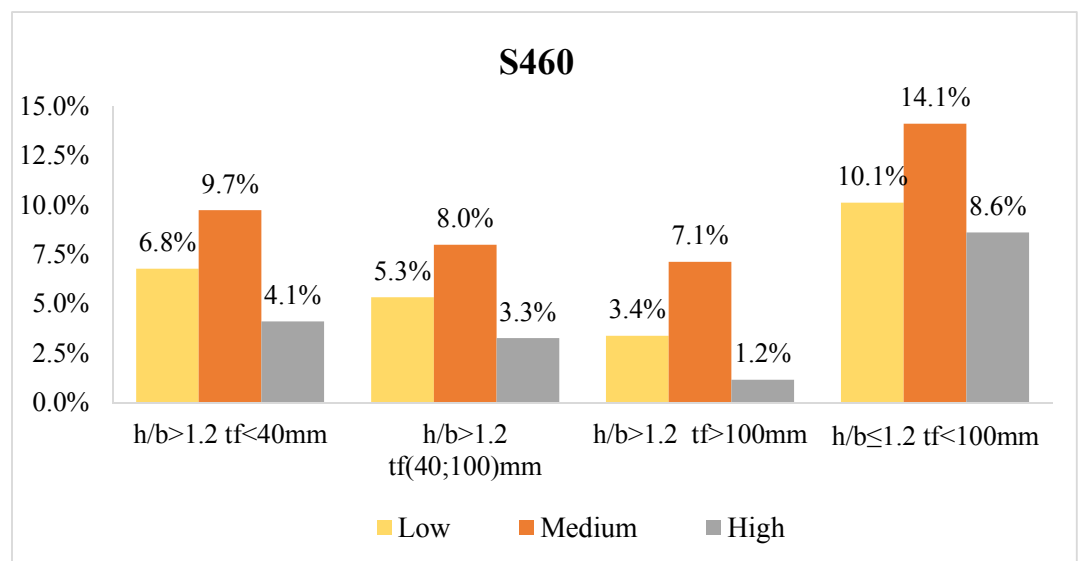

Figure 11. All Results organized by Buckling Curve and Slenderness Division for Hot-rolled Cross Sections and Steel Grade S460 -

Residual Stress Proportional to the Actual Value of $f_{y}$ ( $f_{y}$ according to EN 10025)

\subsubsection{Evaluation of the partial factor considering new imperfection factors for $\mathbf{S 4 6 0}$}

It was already seen that the results for steel grade S460 are significantly higher than those for the other steel grades. A possible improvement can be introduced by considering higher imperfection factors for minor axis flexural buckling as shown in Table 8 (values in bold).

Table 8. New Imperfection Factor for Steel Grade S460, Minor Axis

\begin{tabular}{|c|c|c|c|c|c|c|c|}
\hline \multirow[b]{2}{*}{ Fabrication } & \multirow{2}{*}{\multicolumn{2}{|c|}{ Limits }} & \multirow[b]{2}{*}{ Axis } & \multicolumn{2}{|c|}{ EC3-1-1 } & \multicolumn{2}{|c|}{ (Cajot et al. (2013)) } \\
\hline & & & & $\begin{array}{l}\text { S235 } \\
\text { S355 }\end{array}$ & S460 & $\begin{array}{l}\text { S235 } \\
\text { S355 }\end{array}$ & S460 \\
\hline \multirow{4}{*}{ Rolled } & \multirow{3}{*}{$\begin{array}{l}\hat{\lambda} \\
\hat{\Omega}\end{array}$} & $\mathrm{t}_{\mathrm{f}} \leq 40 \mathrm{~mm}$ & $\begin{array}{l}y-y \\
z-z\end{array}$ & $\begin{array}{l}0.21 \\
0.34\end{array}$ & $\begin{array}{l}0.13 \\
0.21\end{array}$ & - & - \\
\hline & & $\begin{array}{c}40 \mathrm{~mm}<\mathrm{t}_{\mathrm{f}} \leq 1 \\
00 \mathrm{~mm}\end{array}$ & $\begin{array}{l}y-y \\
z-z\end{array}$ & $\begin{array}{l}0.34 \\
0.49 \\
\end{array}$ & $\begin{array}{l}0.21 \\
\mathbf{0 . 3 4}\end{array}$ & - & - \\
\hline & & $\mathrm{t}_{\mathrm{f}}>100 \mathrm{~mm}$ & $\begin{array}{l}y-y \\
z-z\end{array}$ & - & - & $\begin{array}{l}0.34 \\
0.49 \\
\end{array}$ & $\begin{array}{l}0.21 \\
0.34 \\
\end{array}$ \\
\hline & $\frac{\hat{v}}{2} \overrightarrow{\mathrm{v}}$ & $\mathrm{t}_{\mathrm{f}} \leq 100 \mathrm{~mm}$ & $\begin{array}{l}y-y \\
z-z\end{array}$ & $\begin{array}{l}0.34 \\
0.49\end{array}$ & $\begin{array}{l}0.21 \\
\mathbf{0 . 3 4}\end{array}$ & - & - \\
\hline
\end{tabular}

$* \mathrm{~h} / \mathrm{b} \leq 1,2$ and $\mathrm{t}_{\mathrm{f}}>100 \mathrm{mmn}$ is not included in the table, because no cross-sections were found

Figure 12 and Figure 13, similarly to Figure 5 and Figure 6 show the results according to slenderness and buckling curve division, respectively. The improvement of using higher imperfection factors for steel grade S460 is clear. 


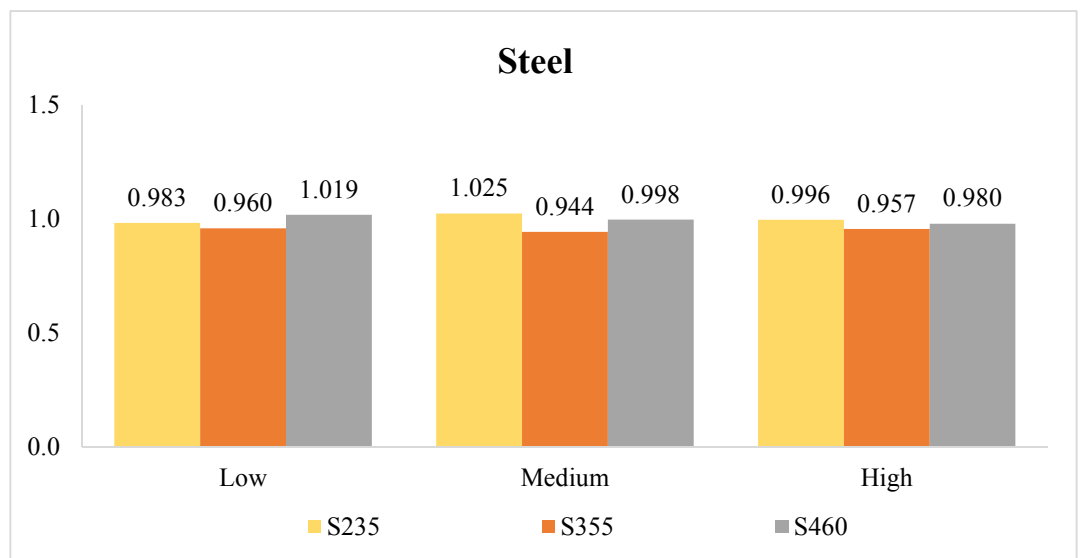

Figure 12. All Results organized by Slenderness for Hot-rolled Cross Sections $-f_{y}$ according to EN 10025 (Table B1, Annex B)

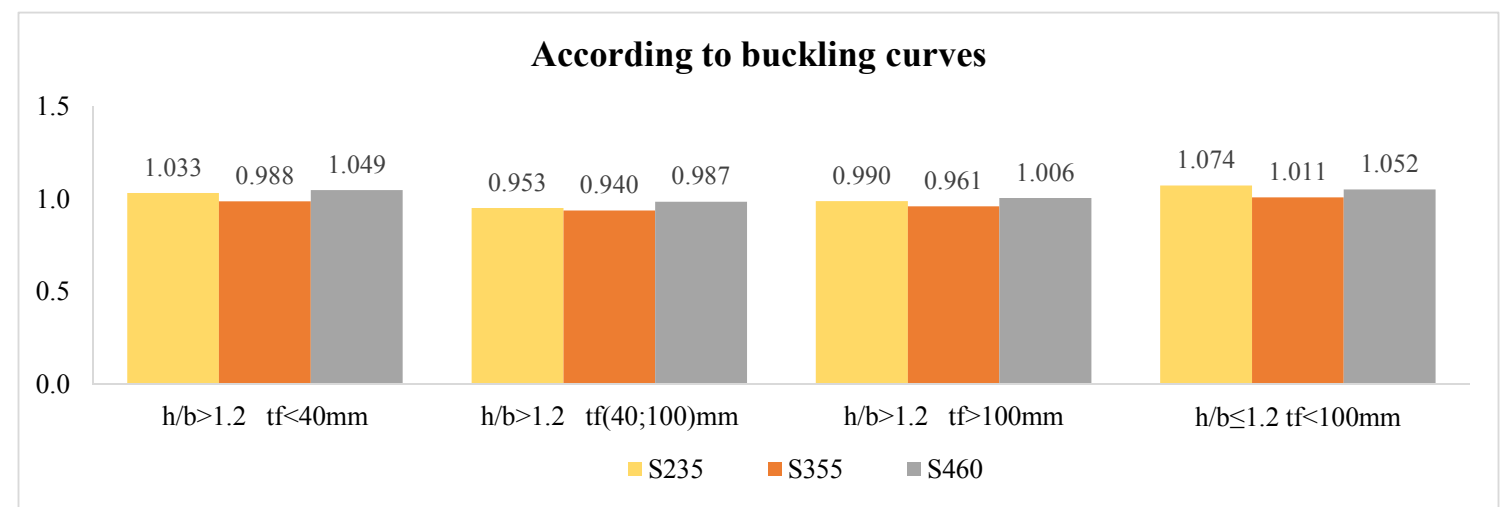

Figure 13. All Results organized by Buckling Curve Division for Hot-rolled Cross sections - $\mathrm{fy}_{\mathrm{y}}$ according to EN 10025 (Table B1, Annex B)

\subsection{Results and Discussion - Major Axis Flexural Buckling}

Identically to minor axis flexural buckling, the safety assessment is computed considering the Annex D procedure and variability of yield stress only, as stated in Section 3.2. The partial factors are also normalized with respect to the average value for $S 235$ and $S 355, t_{f} \leq 40 \mathrm{~mm}, h / b>1.2$ and major axis of flexural buckling. Firstly, the reference cases for hot-rolled cross sections are analysed: the yield stress both in $r_{e}$ and $r_{t}$ is considered according to EN 10025. Unlike minor axis flexural buckling, the relative values of the partial factor are more uniform for the different steel grades (Figure 14). 


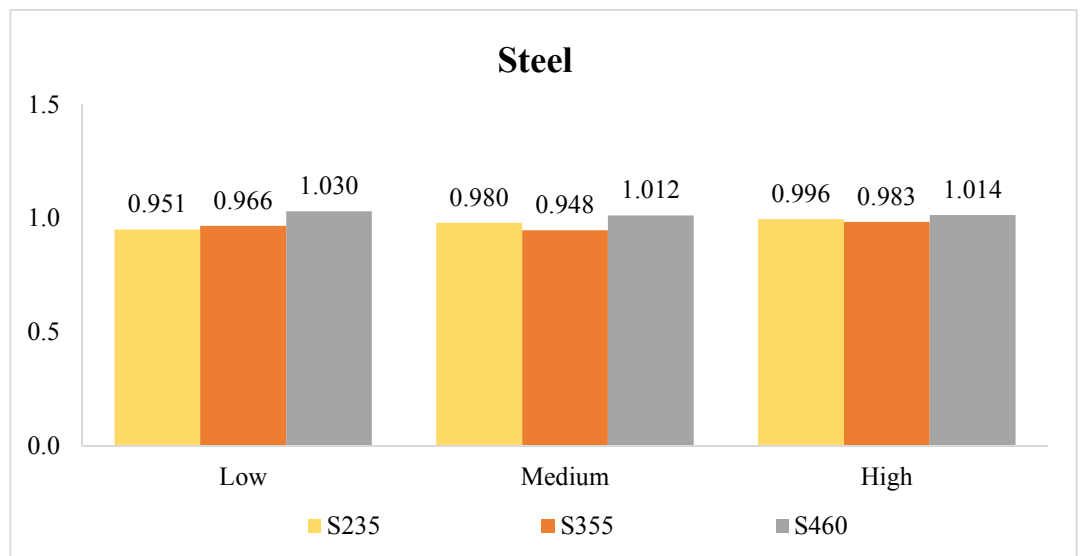

Figure 14. All Results organized by Slenderness for Hot-rolled Cross Sections $-\mathrm{f}_{\mathrm{y}}$ according to EN 10025 (Table A1.1, Annex A1)

Similarly to Figure 6 for minor axis flexural buckling, Figure 15 illustrates the results organized according to the divisions presented in Table 7, regardless of the slenderness range, thus allowing a direct comparison of the buckling curves specified in EC3-1-1. All cases fall within an acceptable range of variation of the partial factor.

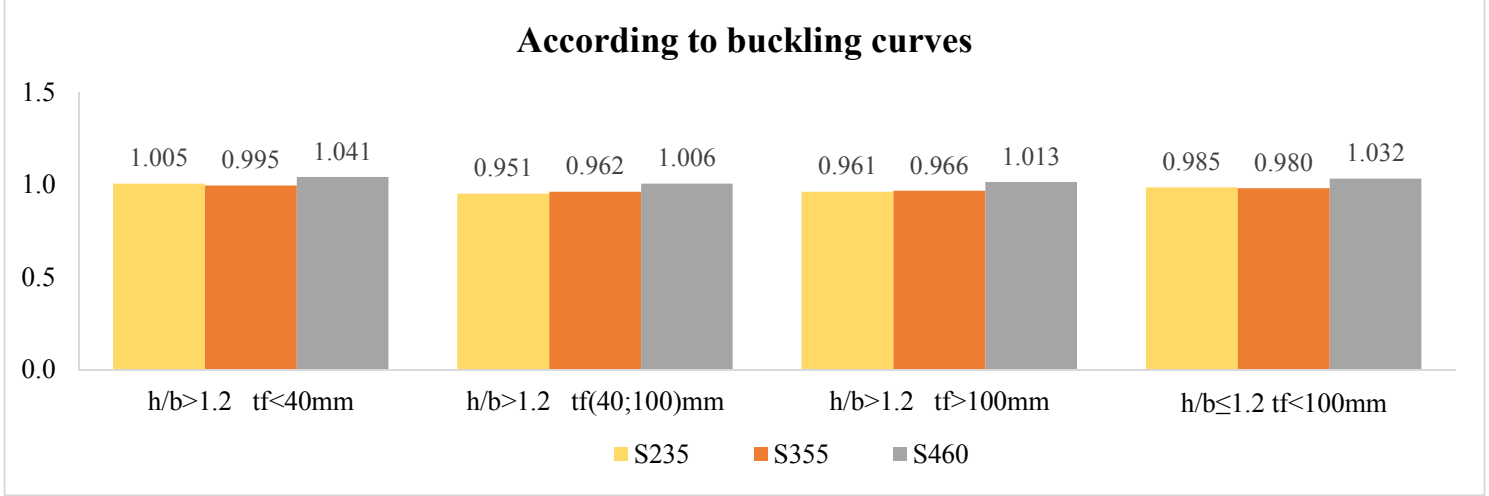

Figure 15. All Results organized by Buckling Curve Division for Hot-rolled Cross Sections $-f_{y}$ according to EN 10025

Furthermore, when the influence of the variation of the yield stress with increasing flange thickness was analysed, similar conclusions were drawn. Identical results were found when the residual stresses were assumed proportional to the yield stress as in Section 3.3.3.

More detailed results are found in Table B1 and Table B2 in Annex B

\subsection{Influence of the Number of Random Variables}

In the previous sub-sections, only $f_{y}$ was considered as a random variable. In reality, in the case on flexural buckling of columns, other basic variables also affect the behaviour of a column, such as the cross-section dimensions and the Young's modulus. It is noted that geometrical and material imperfections such as initial curvature and residual stresses are not included as basic random variables as they are included implicitly in the design model (Simões da Silva et al.) [22].

Hence, the following random variables are included in the analysis:

- $\quad$ Yield stress $-f_{y}$;

- $\quad$ Geometrical dimensions $-b, h, t_{w}, t_{f}$;

- $\quad$ Young's modulus $-E$; 
The distributions of the basic variables are considered as previously presented in Section 2.3. The partial factor is obtained using the procedure proposed in Annex D as presented in Section 2.2 of this document. The influence of the number of basic variables is accounted as their number is gradually increased. The following cases are considered:

- $\quad$ Annex D (fy) - considers the yield stress as the only basic variable, the other parameters are assumed as deterministic quantities with no variability;

- Annex D (fy+CS) - considers the yield stress and the geometrical dimensions of the cross-section as random variables;

- Annex D (fy+CS+E) - considers the yield stress, the geometrical dimensions of the cross-section and the modulus of elasticity as random variables;

$\gamma_{\mathrm{M} 1}$ is calculated for both major and minor axis flexural buckling for all three cases.

\subsubsection{Minor axis flexural buckling}

Figure 16 summarizes the normalized partial factors obtained for minor axis and considering the assumptions previously made. Firstly, as expected, higher values of $\gamma_{\mathrm{M} 1}$ are obtained. Secondly, the rate of increase of $\gamma_{\mathrm{M} 1}$ increases with increasing slenderness: $3.9 \%, 8.0 \%$ and $12.9 \%$ for low, medium and high slenderness, respectively, as Young's modulus and geometrical dimensions (moment of inertia) become more relevant in the medium and high slenderness ranges.

\section{Slenderness}

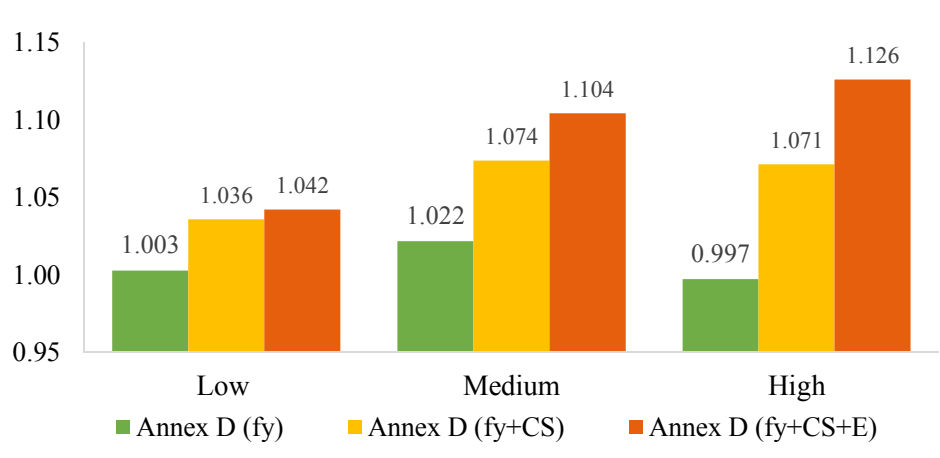

Figure 16. All Steels by Slenderness and using Different Number of Random Variables

Furthermore, results according to subsets of steel grade and slenderness are analysed in Figure 17 for Annex D $\left(f_{y}+C S+E\right)$.

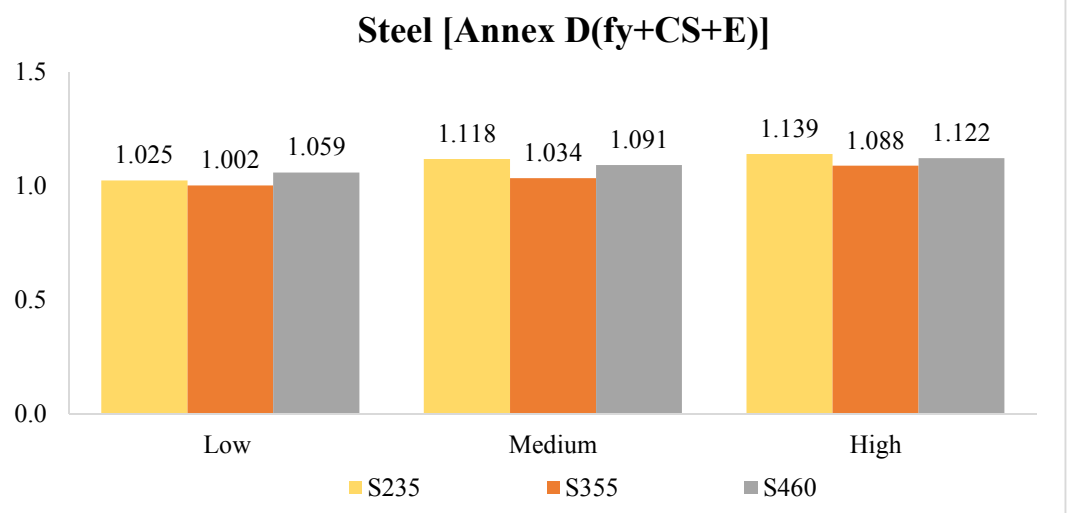

Figure 17. All Results organized by Slenderness and Steel Grade - using fy, Cross-section Dimensions and Modulus of Elasticity as Random Variables (Table B3, Annex B) 
Similarly, results split according to buckling curve and steel grade are given in Figure 18. Detailed results for the intermediate case of Annex D $\left(f_{y}+C S\right)$ are given in Table B3 in Annex B.

According to buckling curves [Annex D(fy+CS+E)]

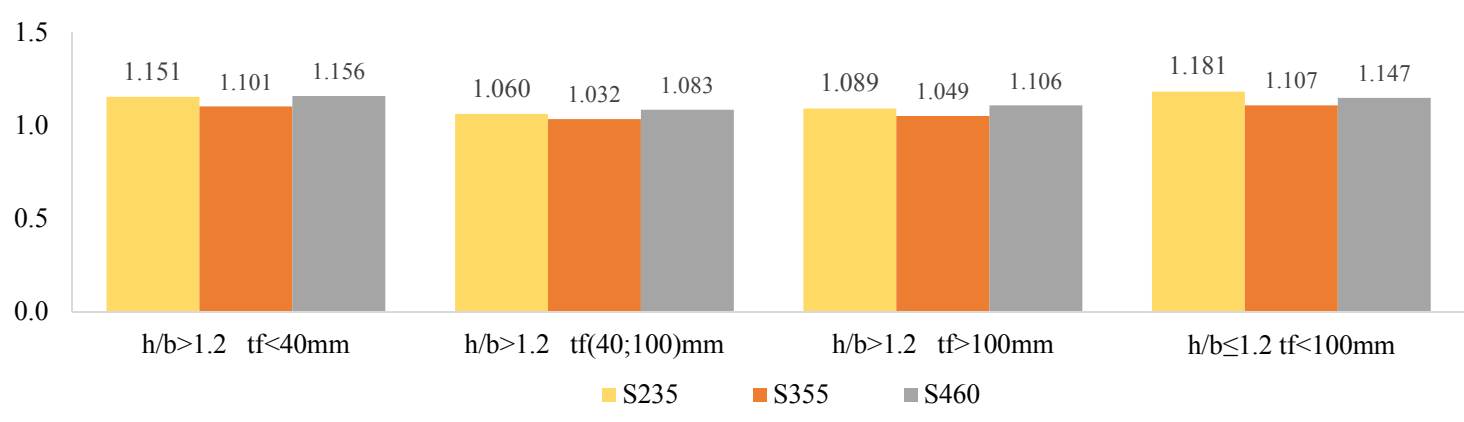

Figure 18. All Results organized by Buckling Curve for Hot-rolled Cross Sections using fy, Cross-section Dimensions and Modulus of Elasticity as Random Variables (see also Table B3, Annex B)

Table B4 in Annex B summarizes the results divided according to steel grade, buckling curve and slenderness range.

While for the yield stress and geometrical dimensions there is certain knowledge about their distributions, it is not the case for the modulus of elasticity. It is a variable, which is very difficult to measure, and additional variability may be added simply because of the measurement method. Therefore, additional calculations were performed for a coefficient of variation of $3 \%$ for the modulus of elasticity (see also Table B3 and Table B4 in Annex B). Differences up to 4\% can be found in the high slenderness range as illustrated on Figure 19 for subsets according to slenderness.

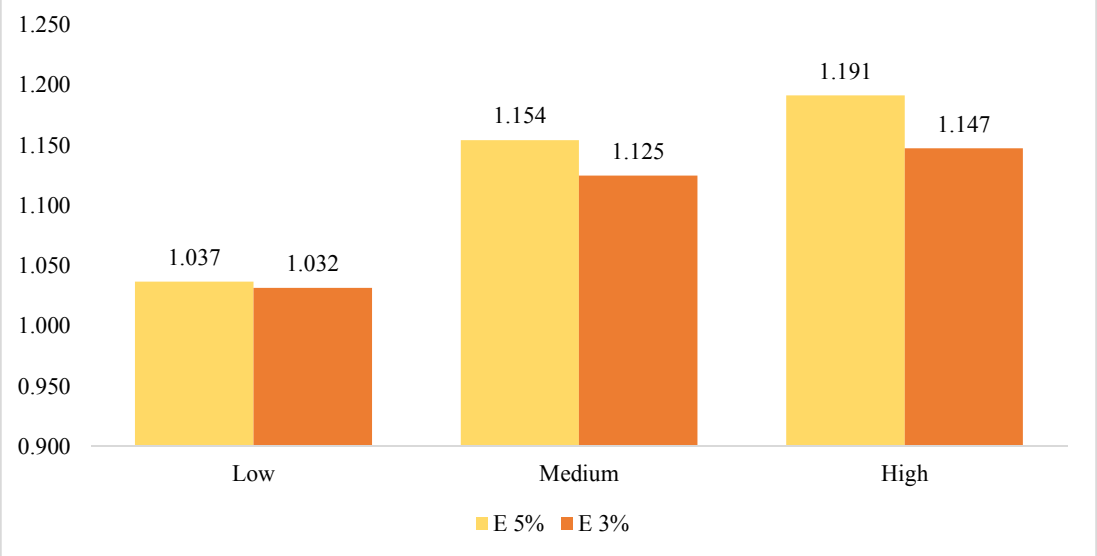

Figure 19. Difference between adopted Coefficients of Variation for E

\subsubsection{Major axis flexural buckling}

The same evaluation was performed for major axis of flexural buckling. The results are similar to the conclusions in the previous section, i.e. the presence of the modulus of elasticity leads to higher values for $\gamma_{\mathrm{M} 1}$ (Figures 20 to 22). However, in general, the values of the $\gamma_{\mathrm{M} 1}$ for major axis flexural buckling are lower than those for minor axis as presented in section 3.5.1 $(3.1 \%, 7.1 \%$ and $11.4 \%$ for low, medium and high slenderness, respectively). Detailed results are given in Table B3 and Table B4 in Annex B. 


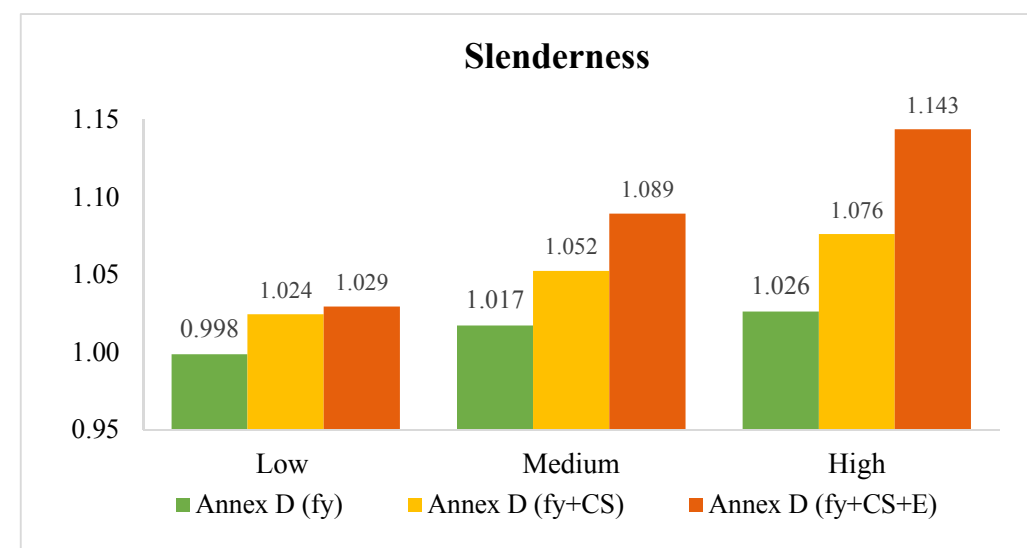

Figure 20. All Steels by Slenderness and using Different Number of Random Variables

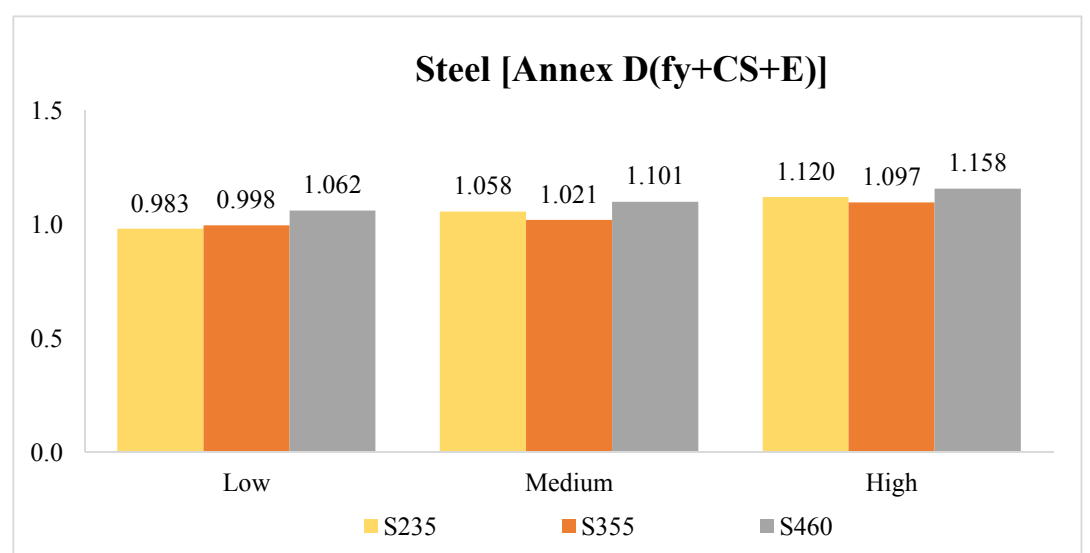

Figure 21. All Results organized by Slenderness and Steel Grade - using fy, Cross-section

Dimensions and Modulus of Elasticity as Random Variables (Table A1.3, Annex A1)

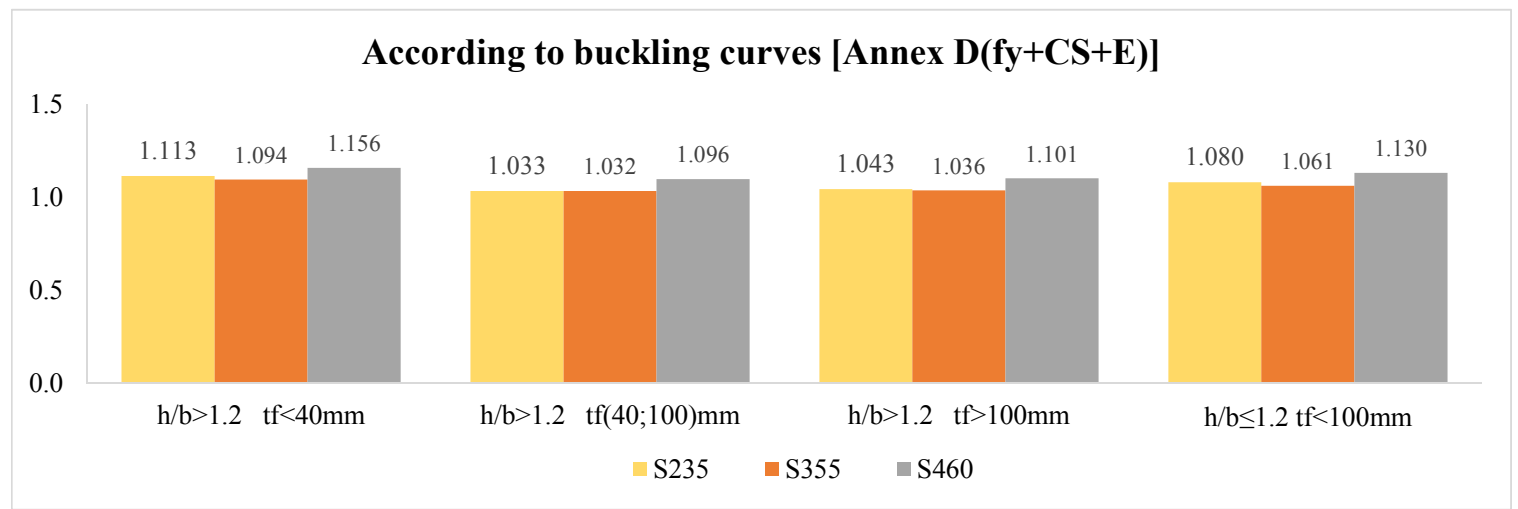

Figure 22. All Results organized by Buckling Curve for Hot-rolled Cross Sections using fy, Cross-section Dimensions and Modulus of Elasticity as Random Variables

\subsection{Summary}

A parametric study to assess the safety of the code prescriptions of the flexural buckling of columns was presented. Table 9 summarizes the relative values obtained per buckling curve, the results being presented as normalized factors with respect to a specific sub-group. 
Table 9. Values of Normalized $\gamma_{\mathrm{M} 1}$ for Flexural Buckling of Columns*

\begin{tabular}{|c|c|c|c|c|c|c|c|}
\hline \multirow[b]{2}{*}{ Fabrication } & \multirow{2}{*}{\multicolumn{2}{|c|}{ Limits }} & \multirow[b]{2}{*}{ Axis } & \multicolumn{2}{|c|}{ EC3-1-1 } & \multicolumn{2}{|c|}{$[19],[20]$} \\
\hline & & & & $\mathbf{S 2 3 5}$ & $\mathrm{S} 460$ & S235 & S460 \\
\hline \multirow{4}{*}{ Rolled } & \multirow{3}{*}{$\hat{\mathrm{N}}$} & $\mathrm{t}_{\mathrm{f}} \leq 40 \mathrm{~mm}$ & $\begin{array}{l}y-y \\
z-z\end{array}$ & $\begin{array}{l}1.000 \\
1.011\end{array}$ & $\begin{array}{l}1.041 \\
\mathbf{1 . 1 4 7}\end{array}$ & - & - \\
\hline & & $40 \mathrm{~mm}<\mathrm{t}_{\mathrm{f}} \leq 100 \mathrm{~mm}$ & $y-y$ & $\begin{array}{l}0.956 \\
0.946\end{array}$ & 1.006 & - & - \\
\hline & & $\mathrm{t}_{\mathrm{f}}>100 \mathrm{~mm}$ & $\begin{array}{l}y-y \\
z-z\end{array}$ & 0.50 & 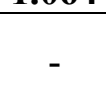 & $\begin{array}{l}0.963 \\
0.975\end{array}$ & $\begin{array}{l}1.013 \\
1.006\end{array}$ \\
\hline & 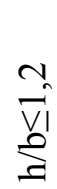 & $\mathrm{t}_{\mathrm{f}} \leq 100 \mathrm{~mm}$ & $\begin{array}{l}y-y \\
z-z\end{array}$ & $\begin{array}{l}0.983 \\
1.042\end{array}$ & $\begin{array}{l}1.032 \\
\mathbf{1 . 1 4 6}\end{array}$ & - & - \\
\hline
\end{tabular}

* The relative value for the partial factor for S235 and S355 is determined as the mean value obtained for S235 and S355

$* * \mathrm{~h} / \mathrm{b} \leq 1,2$ and $\mathrm{t}_{\mathrm{f}}>100 \mathrm{mmn}$ is not included in the table, because no cross-sections were found

The results were analysed in various subsets. The study revealed that the variation in the relative values of the partial factor is not high, except for steel grade S460 and minor axis of flexural buckling (the numbers in bold in Table 9). New imperfection factors were analysed and the results showed good agreement with the ones obtained for S235 and S355. Table 10 summarizes the corresponding normalized partial factors.

Table 10. Values of Normalized $\gamma_{\mathrm{M} 1}$ for Flexural Buckling of Columns*

\begin{tabular}{|c|c|c|c|c|c|c|c|}
\hline \multirow[b]{2}{*}{ Fabrication } & \multirow{2}{*}{\multicolumn{2}{|c|}{ Limits }} & \multirow[b]{2}{*}{ Axis } & \multicolumn{2}{|c|}{ EC3-1-1 } & \multicolumn{2}{|c|}{ [19], [20] } \\
\hline & & & & S235 & S460 & S235 & S460 \\
\hline \multirow{4}{*}{ Rolled } & \multirow{3}{*}{$\begin{array}{l}\hat{\lambda} \\
\hat{\Omega}\end{array}$} & $\mathrm{t}_{\mathrm{f}} \leq 40 \mathrm{~mm}$ & $\begin{array}{l}y-y \\
z-z\end{array}$ & $\begin{array}{l}1.000 \\
1.011 \\
\end{array}$ & $\begin{array}{l}1.041 \\
\mathbf{1 . 0 4 9} \\
\end{array}$ & - & - \\
\hline & & $40 \mathrm{~mm}<\mathrm{t}_{\mathrm{f}} \leq 100 \mathrm{~mm}$ & $\begin{array}{l}y-y \\
z-z\end{array}$ & $\begin{array}{l}0.956 \\
0.946\end{array}$ & $\begin{array}{l}1.006 \\
\mathbf{0 . 9 8 7} \\
\end{array}$ & - & - \\
\hline & & $\mathrm{t}_{\mathrm{f}}>100 \mathrm{~mm}$ & $\begin{array}{l}y-y \\
z-z\end{array}$ & - & - & $\begin{array}{l}0.963 \\
0.975 \\
\end{array}$ & $\begin{array}{l}1.013 \\
1.006 \\
\end{array}$ \\
\hline & 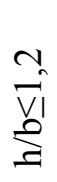 & $\mathrm{t}_{\mathrm{f}} \leq 100 \mathrm{~mm}$ & $\begin{array}{l}y-y \\
z-z\end{array}$ & $\begin{array}{l}0.983 \\
1.042\end{array}$ & $\begin{array}{l}1.032 \\
\mathbf{1 . 0 5 2} \\
\end{array}$ & - & - \\
\hline
\end{tabular}

* The relative value for the partial factor for S235 and S355 is determined as the mean value obtained for S235 and S355

$* * \mathrm{~h} / \mathrm{b} \leq 1,2$ and $\mathrm{t}_{\mathrm{f}}>100 \mathrm{mmn}$ is not included in the table, because no cross-sections were found 
Finally based on the analysis performed in Section 3.5, the normalized values of the partial factor, considering different random variables, is summarized in Table 11. The increase $\gamma_{\mathrm{M} 1}$ in varies from $7.9 \%$ to $11.4 \%$.

Table 11. Values of Normalized $\gamma_{\mathrm{M} 1}$ for Flexural Buckling of Columns*

\begin{tabular}{|c|c|c|c|c|c|c|c|c|c|}
\hline \multirow[b]{2}{*}{ Fabrication } & \multirow{2}{*}{\multicolumn{2}{|c|}{ Limits }} & \multirow{2}{*}{ Axis } & \multicolumn{2}{|c|}{ Annex D (fy) } & \multicolumn{2}{|c|}{ Annex D $(f y+C S)$} & \multicolumn{2}{|c|}{$\begin{array}{c}\text { Annex D } \\
(\text { fy+CS+E) }\end{array}$} \\
\hline & & & & $\begin{array}{l}\text { S235 } \\
\text { S355 }\end{array}$ & S460 & $\begin{array}{l}\text { S235 } \\
\text { S355 }\end{array}$ & S460 & $\begin{array}{l}\text { S235 } \\
\text { S355 }\end{array}$ & S460 \\
\hline \multirow{4}{*}{ Rolled } & \multirow{3}{*}{$\stackrel{\hat{\lambda}}{\hat{\Omega}}$} & $\mathrm{t}_{\mathrm{f}} \leq 40 \mathrm{~mm}$ & $\begin{array}{l}y-y \\
z-z\end{array}$ & $\begin{array}{l}1.000 \\
1.011 \\
\end{array}$ & $\begin{array}{l}1.041 \\
1.049 \\
\end{array}$ & $\begin{array}{l}1.055 \\
1.084 \\
\end{array}$ & $\begin{array}{l}1.104 \\
1.117\end{array}$ & $\begin{array}{l}1.103 \\
1.126 \\
\end{array}$ & $\begin{array}{l}1.156 \\
1.156 \\
\end{array}$ \\
\hline & & $\begin{array}{c}40 \mathrm{~mm}<\mathrm{t}_{\mathrm{f}} \leq 100 \mathrm{~m} \\
\mathrm{~m}\end{array}$ & $\begin{array}{l}y-y \\
z-z\end{array}$ & $\begin{array}{l}0.956 \\
0.946\end{array}$ & $\begin{array}{l}1.006 \\
0.987\end{array}$ & $\begin{array}{l}0.994 \\
1.009\end{array}$ & $\begin{array}{l}1.052 \\
1.047\end{array}$ & $\begin{array}{l}1.033 \\
1.046\end{array}$ & $\begin{array}{l}1.096 \\
1.083\end{array}$ \\
\hline & & $\mathrm{t}_{\mathrm{f}}>100 \mathrm{~mm}$ & $\begin{array}{l}y-y \\
z-z\end{array}$ & $\begin{array}{l}0.963 \\
0.975 \\
\end{array}$ & $\begin{array}{l}1.013 \\
1.006 \\
\end{array}$ & $\begin{array}{l}0.999 \\
1.034 \\
\end{array}$ & $\begin{array}{l}1.055 \\
1.069 \\
\end{array}$ & $\begin{array}{l}1.039 \\
1.069 \\
\end{array}$ & $\begin{array}{l}1.101 \\
1.106 \\
\end{array}$ \\
\hline & 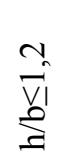 & $\mathrm{t}_{\mathrm{f}} \leq 100 \mathrm{~mm}$ & $\begin{array}{l}y-y \\
z-z\end{array}$ & $\begin{array}{l}0.983 \\
1.042\end{array}$ & $\begin{array}{l}1.032 \\
1.052\end{array}$ & $\begin{array}{l}1.029 \\
1.108\end{array}$ & $\begin{array}{l}1.084 \\
1.114\end{array}$ & $\begin{array}{l}1.071 \\
1.144\end{array}$ & $\begin{array}{l}1.130 \\
1.147\end{array}$ \\
\hline
\end{tabular}

* The relative value for the partial factor for S235 and S355 is determined as the mean value obtained for S235 and S355

$* * \mathrm{~h} / \mathrm{b} \leq 1,2$ and $\mathrm{t}_{\mathrm{f}}>100 \mathrm{mmn}$ is not included in the table, because no cross-sections were found

\section{ASSESSMENT OF THE PARTIAL FACTOR}

Section 3 analysed the design rules for the flexural buckling of columns in terms of the required value of the partial factors $\gamma_{\mathrm{M} 1}$ to match the target probability of failure specified in EN 1990 [2]. The analysis was carried out by normalizing all values with respect to a reference case (major axis flexural buckling of I-section profiles in S235 to S355 with maximum flange thickness of $40 \mathrm{~mm}$ and $h / b>1.2$ ) because the quality of the design rules is very dependent on the scatter of the $\gamma_{\mathrm{M} 1}$ values for the various subsets that may be considered. It was shown that the design rules provide consistent results across the various possible subsets, with small scatter on the value of $\gamma_{\mathrm{M} 1}$.

In this section it is proposed to discuss the adoption of a single global $\gamma_{\mathrm{M} 1}$ for flexural buckling of columns that is in line with the failure probability in EN 1990 and incorporates all the viewpoints that support code drafting and the choice of safety factors [23],[9].

Table 12 summarizes the partial factors obtained for minor and major axis, now given as absolute values instead of normalized values. It is noted that all values are smaller, since the normalizing $\gamma_{\mathrm{M} 1}$ for the reference case is equal to 0.979 . The results are presented according to subsets of steel grade and buckling curve. 
Table 12. Values of $\gamma_{\mathrm{M} 1}$ obtained using Different Random Variables for Major and Minor Axes Flexural Buckling

\begin{tabular}{|c|c|c|c|c|c|c|c|c|c|}
\hline \multirow{2}{*}{$\begin{array}{c}\text { Fabricati } \\
\text { on }\end{array}$} & \multirow{2}{*}{\multicolumn{2}{|c|}{ Limits }} & \multirow{2}{*}{ Axis } & \multicolumn{2}{|c|}{ Annex D (fy) } & \multicolumn{2}{|c|}{$\begin{array}{c}\text { Annex D } \\
(\text { fy+CS) }\end{array}$} & \multicolumn{2}{|c|}{$\begin{array}{c}\text { Annex D } \\
(f y+C S+E)\end{array}$} \\
\hline & & & & $\begin{array}{l}\text { S235 } \\
\text { S355 }\end{array}$ & S460 & $\begin{array}{l}\text { S235 } \\
\text { S355 }\end{array}$ & S460 & $\begin{array}{l}\text { S235 } \\
\text { S355 }\end{array}$ & S460 \\
\hline \multirow{4}{*}{ Rolled } & \multirow{3}{*}{$\frac{\mathfrak{N}}{\hat{\Omega}}$} & $\mathrm{t}_{\mathrm{f}} \leq 40 \mathrm{~mm}$ & $\begin{array}{l}y-y \\
z-z\end{array}$ & $\begin{array}{l}0.979 \\
0.990 \\
\end{array}$ & $\begin{array}{l}1.020 \\
1.028 \\
\end{array}$ & $\begin{array}{l}1.033 \\
1.062 \\
\end{array}$ & $\begin{array}{l}1.081 \\
1.094 \\
\end{array}$ & $\begin{array}{l}1.081 \\
1.103 \\
\end{array}$ & $\begin{array}{l}1.132 \\
1.133 \\
\end{array}$ \\
\hline & & $\begin{array}{c}40 \mathrm{~mm}^{2}<\mathrm{t}_{\mathrm{f}} \leq 10 \\
0 \mathrm{~mm}\end{array}$ & $\begin{array}{l}y-y \\
z-z\end{array}$ & $\begin{array}{l}0.937 \\
0.927\end{array}$ & $\begin{array}{l}0.985 \\
0.967\end{array}$ & $\begin{array}{l}0.974 \\
0.989\end{array}$ & $\begin{array}{l}1.030 \\
1.025\end{array}$ & $\begin{array}{l}1.011 \\
1.025\end{array}$ & $\begin{array}{l}1.074 \\
1.060\end{array}$ \\
\hline & & $\mathrm{t}_{\mathrm{f}}>100 \mathrm{~mm}$ & $\begin{array}{l}y-y \\
z-z\end{array}$ & $\begin{array}{l}0.944 \\
0.955\end{array}$ & $\begin{array}{l}0.992 \\
0.985\end{array}$ & $\begin{array}{l}0.979 \\
1.013\end{array}$ & $\begin{array}{l}1.034 \\
1.047 \\
\end{array}$ & $\begin{array}{l}1.018 \\
1.047\end{array}$ & $\begin{array}{l}1.078 \\
1.084\end{array}$ \\
\hline & $\stackrel{\hat{\Omega}}{\hat{v} \mid} \sim$ & $\mathrm{t}_{\mathrm{f}} \leq 100 \mathrm{~mm}$ & $\begin{array}{l}y-y \\
z-z\end{array}$ & $\begin{array}{l}0.962 \\
1.021\end{array}$ & $\begin{array}{l}1.011 \\
1.030\end{array}$ & $\begin{array}{l}1.008 \\
1.085\end{array}$ & $\begin{array}{l}1.062 \\
1.091\end{array}$ & $\begin{array}{l}1.049 \\
1.120\end{array}$ & $\begin{array}{l}1.107 \\
1.124\end{array}$ \\
\hline
\end{tabular}

In Annex B, Table B5 and Table B6, a further division into subsets according to slenderness is performed in order to be able to compare the different slenderness ranges. Even though finer subsets into slenderness, steel grade and buckling curve are adopted, the partial factors higher than unity are mostly only observed when the Young's modulus is included.

Table 13. Average $\gamma_{\mathrm{M} 1}$ for Minor and Major Axis Flexural Buckling, according to Buckling Curves and Slenderness

\begin{tabular}{|c|c|c|c|c|}
\hline & Axis & Annex D(fy) & Annex D(fy+CS) & Annex D(fy+CS+E) \\
\hline \multirow{2}{*}{ Mean value } & $\mathrm{y}-\mathrm{y}$ & 0.943 & 0.995 & 1.040 \\
\cline { 2 - 5 } & $\mathrm{z}-\mathrm{z}$ & 0.941 & 1.012 & 1.049 \\
\hline \multirow{2}{*}{$\begin{array}{c}\text { Coefficient of } \\
\text { variation }\end{array}$} & $\mathrm{y}-\mathrm{y}$ & $4.28 \%$ & $4.79 \%$ & $6.31 \%$ \\
\cline { 2 - 5 } & $\mathrm{z}-\mathrm{z}$ & $4.33 \%$ & $4.46 \%$ & $5.54 \%$ \\
\hline
\end{tabular}

Table 13 summarizes the mean and standard deviation of $\gamma_{\mathrm{M} 1}$ for the three different sets of random variable that were considered. It is concluded that depending on the random variables included in the analysis (just $\mathrm{f}_{\mathrm{y}}$; $\mathrm{f}_{\mathrm{y}}$ and cross-section geometry; or $\mathrm{f}_{\mathrm{y}}$, cross-section geometry and modulus of elasticity E) the average value of $\gamma_{\mathrm{M} 1}$ varies from 0.941 to 1.049 with the c.o.v varying from $4.3 \%$ to $6.3 \%$. The mean value is lower than 1.05 for the more unfavourable case and the c.o.v. is low. Additionally, in general, the values of the $\gamma_{\mathrm{M} 1}$ for major axis flexural buckling are similar to those for minor axis.

Recalling that the currently recommended value of $\gamma_{\mathrm{M} 1}$ in Eurocode 3, part 1, is 1.0, and comparing with available data from the literature that led to the choice of $\gamma_{\mathrm{M} 1}=1.0$, the results presented in this report for $\gamma_{\mathrm{M} 1}$ are lower. In Muller (2003), a study on the flexural buckling resistance of hot-rolled sections was done and the corresponding partial factors were assessed, see Figure 23, corresponding to an average value of $\gamma_{\mathrm{M} 1}$ for minor axis flexural buckling of 1.097 (cf. 0.941 as these results only considered the variability of $f_{y}$ ). 
It is interesting to note that the observed trend (also in Muller (2003) [24]) of an increasing value of $\gamma_{\mathrm{M} 1}$ in the intermediate slenderness range disappears when variability in cross-section and Young's modulus is included: in this case the value of $\gamma_{\mathrm{M} 1}$ increases monotonically with slenderness. It is noted that the higher value of $\gamma_{\mathrm{M} 1}$ for high slenderness is not so relevant because of practical reasons (practical range of column slenderness), as the parametric study included normalised slenderness $(\bar{\lambda})$ up to 2.5 . It is therefore recommended to keep $\gamma_{\mathrm{M} 1}=1.0$ for columns.

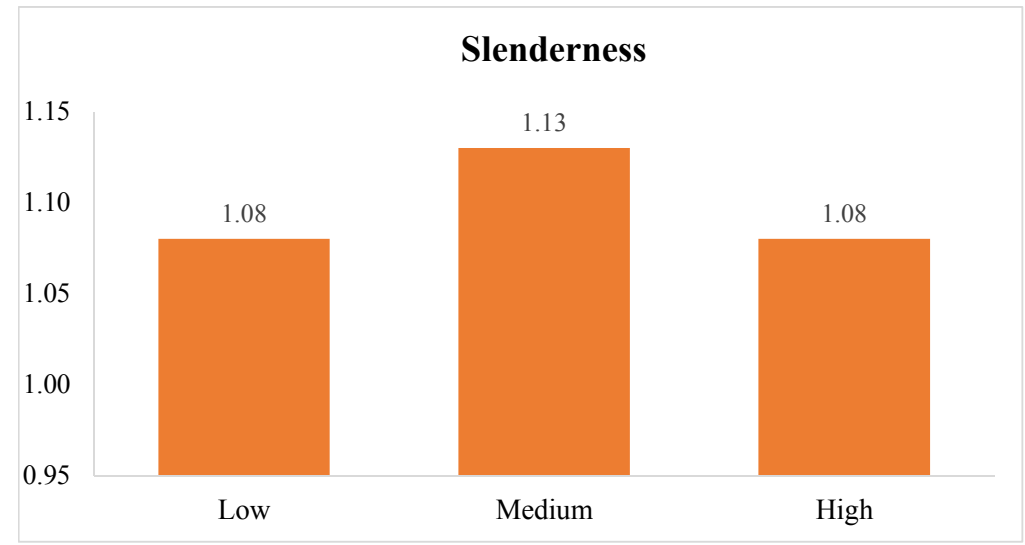

Figure 23. Results by Muller [24]

\section{CONCLUSIONS}

In this paper, the safety assessment of EC3-1-1 rules for flexural buckling of columns with hot-rolled I-shaped cross sections was performed and the partial factor was evaluated considering several subsets, including slenderness ranges, level of yield stress, EC3-1-1 buckling curves; flange thickness and respective variation of the yield stress; buckling axis.

The following conclusions were achieved:

- Influence of the adopted minimum yield stress using EN 10025 or Table 3.1 of Eurocode3;

The level of the minimum yield stress was assessed for both minor and major axis of flexural buckling of hot-rolled columns. It was shown that in both cases the values proposed in EC3 can be up to 8\% non-conservative, which itself is not a negligible difference.

- Influence of the level of the residual stresses adopted in the numerical models;

The buckling curves are currently calibrated for level of residual stresses proportional to the yield stress $f_{y}$, which was shown to be conservative. When the results were divided into slenderness - in the medium slenderness range, where the residual stresses are actually important, high differences were obtained. These variations are relevant for the group of buckling curves S235-S420, with increasing difference as the steel grade increases; about $8 \%$ were noticed for $\mathrm{S} 355$.

- Imperfection factor for flexural-buckling of columns about minor axis which are made of steel grade S460;

It was shown that the imperfection factor currently prescribed for flexural buckling of steel columns made of S460 about the minor axis is not adequate. Alternative analysis was performed in order to check if other curves are more suitable and the results are summarized in Table 14: 
Table 14. New Imperfection Factor for Steel Grade S460, Minor Axis

\begin{tabular}{|c|c|c|c|c|c|c|c|}
\hline \multirow[b]{2}{*}{ Fabrication } & \multirow{2}{*}{\multicolumn{2}{|c|}{ Limits }} & \multirow[b]{2}{*}{ Axis } & \multicolumn{2}{|c|}{ EC3-1-1 } & \multicolumn{2}{|c|}{ [19], [20] } \\
\hline & & & & S235 & S460 & S235 & S460 \\
\hline \multirow{4}{*}{ Rolled } & \multirow{3}{*}{ 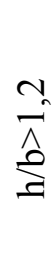 } & $\mathrm{t}_{\mathrm{f}} \leq 40 \mathrm{~mm}$ & $\begin{array}{l}y-y \\
z-z\end{array}$ & $\begin{array}{l}0.21 \\
0.34\end{array}$ & $\begin{array}{l}0.13 \\
\mathbf{0 . 2 1}\end{array}$ & - & - \\
\hline & & $40 \mathrm{~mm}<\mathrm{t}_{\mathrm{f}} \leq 100 \mathrm{~mm}$ & $\begin{array}{l}y-y \\
z-z\end{array}$ & $\begin{array}{l}0.34 \\
0.49\end{array}$ & $\begin{array}{l}0.21 \\
\mathbf{0 . 3 4}\end{array}$ & - & - \\
\hline & & $\mathrm{t}_{\mathrm{f}}>100 \mathrm{~mm}$ & $\begin{array}{l}y-y \\
z-z\end{array}$ & - & - & $\begin{array}{l}0.34 \\
0.49 \\
\end{array}$ & $\begin{array}{l}0.21 \\
0.34\end{array}$ \\
\hline & 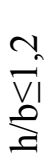 & $\mathrm{t}_{\mathrm{f}} \leq 100 \mathrm{~mm}$ & $\begin{array}{l}y-y \\
z-z\end{array}$ & $\begin{array}{l}0.34 \\
0.49\end{array}$ & $\begin{array}{l}0.21 \\
\mathbf{0 . 3 4}\end{array}$ & - & - \\
\hline
\end{tabular}

- $\quad$ The recent study presented in [19], [20] about buckling curves for heavy sections was confirmed - the buckling curves chosen for sections with $\mathrm{h} / \mathrm{b}>1,2$ and $\mathrm{t}_{\mathrm{f}}>100 \mathrm{~mm}$ are found suitable;

Finally, the value of the partial factor was discussed. With the proposed modifications, it is recommended to keep $\gamma_{\mathrm{M} 1}=1.0$ for columns.

\section{ACKNOWLEDGMENTS}

The research leading to these results has received funding from:

- the European Community's Research Fund for Coal and Steel (RFCS) under grant agreement SAFEBRICTILE RFS-PR-12103 - SEP no. 601596;

- the Portuguese Foundation for Science and Technology (FCT) under grant agreement TAPERSTEEL PTDC/ECM-EST/1970/2012 and

- the Portuguese Foundation for Science and Technology (FCT) under grant agreement SFRH/BD/99702/2014.

\section{NOTATIONS}

Latin upper case letters

A $\quad$ is the gross cross sectional area;

$\mathrm{A}_{\mathrm{eff}} \quad$ is the effective cross sectional area;

$\mathrm{N}_{\mathrm{b}, \mathrm{i}, \mathrm{Rd}} \quad$ is the design buckling resistance about $i$ axis of the compression member;

$\mathrm{N}_{\mathrm{cr}, \mathrm{i}} \quad$ is the critical compressive axial force for buckling about $i$ axis;

$\mathrm{N}_{\mathrm{Ed}} \quad$ is the design value of the axial force;

$\mathrm{N}_{\mathrm{Rk}} \quad$ is the characteristic resistant axial force;

$V_{\delta} \quad$ Estimator for the coefficient of variation of the error term

$V_{X} \quad$ Coefficient of variation

$X_{m} \quad$ Array of mean values of basic variables 
Latin lower case letters

$b \quad$ Correction factor

$g_{r t}(\underline{X})$ Resistance function used as a design model

$k_{d, n} \quad$ Design fractile factor

$n \quad$ Number of experiments or numerical results

$r_{d} \quad$ Design value of the resistance

$r_{e} \quad$ Experimental resistance value

$r_{n} \quad$ Nominal value of the resistance

$r_{t} \quad$ Theoretical resistance determined with $g_{r t}(\underline{X})$

$s \quad$ Estimated value for the standard deviation $\sigma$

$s \Delta \quad$ Estimated value for the standard deviation $\sigma_{\Delta}$

Greek upper case letters

$\begin{array}{ll}\Delta & \text { Logarithm of the error term } \delta \\ \bar{\Delta} & \text { Estimated value for } \mathrm{E}(\Delta)\end{array}$

Greek lower case letters

$\alpha_{\mathrm{i}} \quad$ is the imperfection factor for flexural buckling about $i$ axis;

$\delta \quad$ Error term

$\delta_{i} \quad$ Observed error term for test specimen i

$\eta_{\mathrm{i}} \quad$ is the generalized imperfection for flexural buckling about $i$ axis;

$\bar{\lambda}_{i} \quad$ is the non-dimensional slenderness for flexural buckling about $i$ axis;

$\chi_{\mathrm{i}} \quad$ is the reduction factor for flexural buckling about $i$ axis.

$\sigma \quad$ Standard deviation

$\sigma_{\Delta}^{2} \quad$ Variance of the term $\Delta$

\section{REFERENCES}

[1] Eurocode - EN 1993-1-1, Eurocode 3: Design of Steel Structures - Part 1-1: General Rules and Rules for Buildings CEN, Brussels, 2005.

[2] Eurocode - EN 1990, Eurocode - Basis of Structural Design, CEN, Brussels, 2002.

[3] Simões da Silva, L., Marques, L., Tankova, T., "On the Safety of Stability Design Rules for Steel Members", ICASS 2015, The Eight International Conference on Advances in Steel Structures, July 2015, Lisbon, Portugal

[4] Dowling, P.J., "EC3, The New Eurocode for Steel Structures", in IABSE Conference on Structural Eurocodes, Davos, 1992, pp.159-166.

[5] Sfintesco, D., "Fondement Expérimental des Coubres Européennes de Flambement", Construction Métallique, 1970, No. 3, pp. 5-12.

[6] Beer, H. and Schulz, G., "Bases Théoriques des Courbes Européennes de Flambement", Construction Métallique, 1970, No. 3, pp. 37-57.

[7] Strating, J. and Vos, H., "Simulation sur Ordinateur de la Coubre C.E.E.M de Flambement á l'aide de la Méthode de Monte-Carlo", Construction Métallique, 1973, No. 2, pp. 23-39.

[8] Maquoi, R. and Rondal, J., "Mise en Équation des Nouvelles Courbes Européennes de Flambement", Construction Métallique, 1978, No. 1 pp. 17-30.

[9] Tankova, T., Simões da Silva, L., Marques, L., Rebelo, C. and Taras, A., "Towards a Standardized Procedure for the Safety Assessment of Stability Design Rules", Journal of Constructional Steel Research, 2014, Vol. 103, pp. 290-302.

[10] Simões da Silva, L., Rebelo C., Nethercot D. Marques, L., Simões, R. and Vila Real, 
P.M.M., "Statistical Evaluation of the Lateral-Torsional Buckling Resistance of Steel I-beams, Part 2: Variability of Steel Properties, Journal of Constructional Steel Research, 2009, Vol. 65, pp. 832-849.

[11] Braconi, A., Finetto, M., Degee, H., Hausoul, N., Gundel, M., Hffmeister, B., Varelis, G., Pappa, P., Karmanos, S.A., Obiala, R., Rinaldi, V., Somja, H., Hjaij, M., Badalassi, M., Caprili, S. and Salvatore, W., "OPUS - Optimising the Seismic Performance of Steel and Steel-concrete Structures" Standardising Material Quality Control, Final Report, Research Fund for Coal and Steel, Contract Agreement RFSR-CT-2007-00039, 2013.

[12] CEN. European Committee for Standardization, EN 10025: 2004 - Hot Rolled Products of Structural Steels, 2004.

[13] Alpsten, G., "Variations in Mechanical and Cross-sectional Properties of Steel, State of the Art Report, Proceedings of the International Conference on the Planning and Design of Tall Buildings”, ASCE-IABSE, Lehigh University, August 1972.

[14] Taras, A., "Contribution to the Development of Consistent Stability Design Rules for Steel Members", PhD Thesis, Technical University of Graz, Graz, Austria, 2010.

[15] Cajot, L.G., Haller, M., Conan, Y., Sedlacek, G., Kraus, O., Rondla, J., Cerfontaine, F., Johansson, B. and Lagerqvist, O., "PROQUA - Probablistic Quantification of Safety of a Steel Structure Highlighting the Potential of Steel Versus Other Materials", Final Report, Technical Steel Research, Contract No. 7210-PR/249, 2005.

[16] DNV, Guideline for Offshore Structural Reliability Analysis - Chapter 7, DNV Report No. 95-2018, Det Norske Veritas, Hovik, Norway, 1995.

[17] Abaqus, v.6.12, Dassault Systems/Simulia, Providence, RI, USA, 2012.

[18] ECCS, "European Recommendations for Steel Construction”, Brussels, 1978.

[19] Snijder, H.H., Cajot, L.G., Poppa, N. and Spoorenberg, R.C., "Buckling Curves for Heavy Wide Flange Steel Columns", Romanian Journal of Technical Sciences, Applied Mechanics, 2014, Vol. 59, (1/2), pp. 178-204

[20] Spoorenberg, R.C., Snijder, H.H., Cajot, L.-G. and Popa, N., "Buckling Curves for Heavy Wide Flange QST Columns based on Statistical Evaluation", Journal of Constructional Steel Research, 2014, Vol. 101, pp. 280-289.

[21] Lindner, J., "Classification of Rolled I-profiles Fabricated in Steel Grade S460 within Table 6.2 of EN 1993-1-1 - Rev.3. Report to Working Group 1-1, 21/02/2015.

[22] Simões da Silva, L., Simões, R., Gervásio, H. and Couchman, G., "Design of Steel Structures. Eurocode3: Design of Steel Structures. Part-1-1 - General Rules and Rules for Buildings. UK Edition ECCS - European Convention for Constructional Steelwork, John Wiley \& Sons and SCI- Steel Construction Institute, 2014.

[23] Gulvanessian, H., Calgaro, J-A. and Holicky, M., "Designers' Guide to EN 1990. Eurocode: Basis of Design”, Thomas Telford, ISBN: 0727730118, 2002.

[24] Muller, C., "Zum Nachweis ebener Tragwerke aus Stahl gegen seitliches Ausweichen, PhD Dissertation", Schriftenreihe Stahlbau - RWTH Aachen, 2003. 


\section{Annex A - Statistical Distributions for the Yield Stress}

The statistical distributions of the yield stress were chosen based on real experiments. The variation adopted for S235 and S355 is based on a previously performed study at the University of Coimbra [10]. It is summarized in Table A1:

Table A1. Results from

\begin{tabular}{|c|c|c|c|c|c|c|c|c|c|}
\hline $\begin{array}{c}\text { Steel } \\
\text { Grade }\end{array}$ & $\mathbf{t f}(\mathrm{mm})$ & $\begin{array}{c}\mathbf{f y} \\
(\mathbf{M P a})\end{array}$ & $\mathbf{n}$ & $\begin{array}{l}\text { Mean } \\
\text { (MPa) }\end{array}$ & $\begin{array}{l}\text { St. Dev } \\
\text { (MPa) }\end{array}$ & CoV & $\begin{array}{l}\text { Minimum } \\
\text { Value } \\
\text { (MPa) }\end{array}$ & $\begin{array}{l}\text { Quantile } \\
\text { for the } \\
\text { nominal } \\
\text { value }\end{array}$ & $\begin{array}{c}\text { Value } \\
\text { for } \\
99.9 \% \\
\text { quantile }\end{array}$ \\
\hline \multirow{3}{*}{ S235 } & \multirow{3}{*}{$\leq 16$} & \multirow{3}{*}{235} & 837 & 310.03 & 31.29 & $10.09 \%$ & 239.2 & 99.17 & 213.32 \\
\hline & & & 347 & 279.78 & 18.79 & $6.72 \%$ & 239.2 & 99.14 & 221.70 \\
\hline & & & 342 & 297.30 & 17.11 & $5.76 \%$ & 258 & 99.99 & 244.41 \\
\hline \multirow{4}{*}{$\begin{array}{c}\text { S275 } \\
(n=3625)\end{array}$} & $\leq 16$ & 275 & 1991 & 327.93 & 18.96 & $5.78 \%$ & - & 99.74 & 269.35 \\
\hline & $>16 \leq 40$ & 265 & 2342 & 306.28 & 15.63 & $5.10 \%$ & - & 99.59 & 257.97 \\
\hline & $>40 \leq 63$ & 255 & 71 & 299.23 & 14.07 & $4.70 \%$ & - & 99.92 & 255.74 \\
\hline & $>63 \leq 80$ & 245 & 21 & 290.38 & 9.68 & $3.33 \%$ & - & 100.00 & 260.46 \\
\hline \multirow{4}{*}{$\begin{array}{c}\text { S355 } \\
(n=1979)\end{array}$} & $\leq 16$ & 355 & 733 & 419.38 & 20.25 & $4.83 \%$ & - & 99.93 & 356.80 \\
\hline & $>16 \leq 40$ & 345 & 1146 & 395.82 & 15.16 & $3.83 \%$ & - & 99.96 & 348.96 \\
\hline & $>40 \leq 63$ & 335 & 77 & 380.51 & 10.01 & $2.63 \%$ & - & 100.00 & 349.58 \\
\hline & $>63 \leq 80$ & 325 & 23 & 361.87 & 10.25 & $2.83 \%$ & - & 99.98 & 330.20 \\
\hline
\end{tabular}

For S460, recent results from OPUS [15] were used. They are summarized in Table A2.

Table A2. Results from OPUS

\begin{tabular}{|c|c|c|c|c|c|c|c|c|c|}
\hline $\begin{array}{c}\text { Steel } \\
\text { Grade }\end{array}$ & tf $(\mathrm{mm})$ & $\begin{array}{c}\mathbf{f y} \\
(\mathbf{M P a})\end{array}$ & n & $\begin{array}{l}\text { Mean } \\
\text { (MPa) }\end{array}$ & $\begin{array}{l}\text { St. Dev } \\
\text { (MPa) }\end{array}$ & $\mathrm{CoV}$ & $\begin{array}{c}\text { Minimum } \\
\text { Value } \\
\text { (MPa) }\end{array}$ & $\begin{array}{l}\text { Quantile } \\
\text { for the } \\
\text { nominal } \\
\text { value }\end{array}$ & $\begin{array}{c}\text { Value } \\
\text { for } \\
99.9 \% \\
\text { quantile }\end{array}$ \\
\hline \multirow{3}{*}{$\begin{array}{c}S 460 \\
(n=982)\end{array}$} & $<16$ & 460 & 113 & 495.26 & 17.2 & $3.47 \%$ & \multirow{3}{*}{$\begin{array}{c}\text { not } \\
\text { available }\end{array}$} & 97.98 & 442.11 \\
\hline & $>16 \leq 40$ & 440 & 778 & 520.88 & 26.8 & $5.15 \%$ & & 99.87 & 438.06 \\
\hline & $>40 \leq 63$ & 430 & 91 & 486.4 & 43.5 & $8.94 \%$ & & 90.26 & 351.97 \\
\hline
\end{tabular}




\section{Annex B - Results}

Table B1. All Results for Minor and Major Axis of Hot-rolled Sections, Normalized $\gamma_{\mathrm{M} 1}$ with respect to the Average Value for $\mathrm{S} 235 / \mathrm{S} 355 \mathrm{t}_{\mathrm{f}} \leq 40 \mathrm{~mm}, \mathrm{~h} / \mathrm{b}>1.2$ and Major Axis of Flexural Buckling (the Values in Green)

\begin{tabular}{|c|c|c|c|c|c|c|c|c|c|}
\hline \multirow{3}{*}{ Sub-set } & & \multicolumn{5}{|c|}{ Minor axis } & \multicolumn{3}{|c|}{ Major axis } \\
\hline & & \multirow[b]{2}{*}{$\mathbf{n}$} & \multirow[b]{2}{*}{ EN10025 } & \multicolumn{3}{|c|}{ EN10025 } & \multicolumn{3}{|c|}{ EN10025 } \\
\hline & & & & EN10025(S460) & $\mathbf{f}_{\mathbf{y i}}$ & EC3 & EN10025 & $\mathbf{f}_{\mathbf{y i}}$ & EC3 \\
\hline Total & & 1833 & 1.113 & 1.039 & 1.198 & 1.146 & 1.033 & 1.055 & 1.062 \\
\hline Low & & 564 & 1.056 & 1.003 & - & - & 0.993 & - & - \\
\hline Medium & & 705 & 1.127 & 1.022 & - & - & 1.012 & - & - \\
\hline High & & 564 & 1.075 & 0.997 & - & - & 1.021 & - & - \\
\hline S235 & & 611 & 1.032 & 1.032 & 1.032 & 1.058 & 0.995 & 0.995 & 1.020 \\
\hline S355 & & 611 & 0.988 & 0.988 & 1.033 & 1.010 & 0.993 & 1.001 & 1.013 \\
\hline $\mathrm{S} 460$ & & 611 & 1.127 & 1.034 & 1.247 & 1.174 & 1.034 & 1.062 & 1.073 \\
\hline \multirow{3}{*}{ S235 } & Low & 188 & 0.983 & 0.983 & 0.983 & 1.016 & 0.951 & 0.951 & 0.985 \\
\hline & Medium & 235 & 1.025 & 1.025 & 1.025 & 1.045 & 0.980 & 0.980 & 0.999 \\
\hline & High & 188 & 0.996 & 0.996 & 0.996 & 1.003 & 0.996 & 0.996 & 1.000 \\
\hline \multirow{3}{*}{ S355 } & Low & 188 & 0.960 & 0.960 & 0.997 & 0.988 & 0.966 & 0.973 & 0.995 \\
\hline & Medium & 235 & 0.944 & 0.944 & 1.008 & 0.960 & 0.948 & 0.970 & 0.960 \\
\hline & High & 188 & 0.957 & 0.957 & 0.975 & 0.961 & 0.983 & 0.986 & 0.986 \\
\hline \multirow{3}{*}{ S460 } & Low & 188 & 1.089 & 1.019 & 1.183 & 1.153 & 1.030 & 1.051 & 1.082 \\
\hline & Medium & 235 & 1.142 & 0.998 & 1.275 & 1.175 & 1.012 & 1.057 & 1.035 \\
\hline & High & 188 & 1.076 & 0.980 & 1.126 & 1.082 & 1.014 & 1.022 & 1.017 \\
\hline \multirow{4}{*}{ S235 } & $\mathrm{h} / \mathrm{b}>1.2 \quad \mathrm{t}_{\mathrm{f}}<40 \mathrm{~mm}$ & 169 & 1.033 & 1.033 & 1.033 & 1.102 & 1.005 & 1.005 & 1.077 \\
\hline & $\mathrm{h} / \mathrm{b}>1.2 \mathrm{t}_{\mathrm{f}}(40 ; 100) \mathrm{mm}$ & 169 & 0.953 & 0.953 & 0.953 & 0.953 & 0.951 & 0.951 & 0.951 \\
\hline & $\mathrm{h} / \mathrm{b}>1.2 \quad \mathrm{t}_{\mathrm{f}}>100 \mathrm{~mm}$ & 104 & 0.990 & 0.990 & 0.990 & 0.990 & 0.961 & 0.961 & 0.961 \\
\hline & $\mathrm{h} / \mathrm{b} \leq 1.2 \mathrm{t}_{\mathrm{f}}<100 \mathrm{~mm}$ & 169 & 1.074 & 1.074 & 1.074 & 1.097 & 0.985 & 0.985 & 1.006 \\
\hline \multirow{4}{*}{ S355 } & $\mathrm{h} / \mathrm{b}>1.2 \quad \mathrm{t}_{\mathrm{f}}<40 \mathrm{~mm}$ & 169 & 0.988 & 0.988 & 1.034 & 1.029 & 0.995 & 1.009 & 1.036 \\
\hline & $\mathrm{h} / \mathrm{b}>1.2 \mathrm{t} \mathrm{f}(40 ; 100) \mathrm{mm}$ & 169 & 0.940 & 0.940 & 0.962 & 0.962 & 0.962 & 0.965 & 0.982 \\
\hline & $\mathrm{h} / \mathrm{b}>1.2 \quad \mathrm{t}_{\mathrm{f}}>100 \mathrm{~mm}$ & 104 & 0.961 & 0.961 & 0.981 & 0.961 & 0.966 & 0.968 & 0.966 \\
\hline & $\mathrm{h} / \mathrm{b} \leq 1.2 \mathrm{t}_{\mathrm{r}}<100 \mathrm{~mm}$ & 169 & 1.011 & 1.011 & 1.070 & 1.043 & 0.980 & 0.985 & 1.009 \\
\hline \multirow{4}{*}{ S460 } & $\mathrm{h} / \mathrm{b}>1.2 \quad \mathrm{t}_{\mathrm{f}}<40 \mathrm{~mm}$ & 169 & 1.147 & 1.049 & 1.270 & 1.223 & 1.041 & 1.084 & 1.120 \\
\hline & $\mathrm{h} / \mathrm{b}>1.2 \mathrm{t}_{\mathrm{f}}(40 ; 100) \mathrm{mm}$ & 169 & 1.064 & 0.987 & 1.155 & 1.115 & 1.006 & 1.017 & 1.048 \\
\hline & $\mathrm{h} / \mathrm{b}>1.2 \quad \mathrm{t}_{\mathrm{f}}>100 \mathrm{~mm}$ & 104 & 1.006 & 1.006 & 1.064 & 1.006 & 1.013 & 1.027 & 1.013 \\
\hline & $\mathrm{h} / \mathrm{b} \leq 1.2 \mathrm{t}_{\mathrm{f}}<100 \mathrm{~mm}$ & 169 & 1.146 & 1.052 & 1.332 & 1.213 & 1.032 & 1.074 & 1.090 \\
\hline \multirow{6}{*}{$\mathrm{S} 235$} & $0<\mathrm{t}_{\mathrm{f}} \leq 16$ & 91 & 1.032 & 1.032 & 1.032 & 1.032 & 0.996 & 0.996 & 0.996 \\
\hline & $16<\mathrm{t}_{\mathrm{f}} \leq 40$ & 182 & 1.043 & 1.043 & 1.043 & 1.120 & 1.026 & 1.026 & 1.099 \\
\hline & $40<\mathrm{tf}_{\mathrm{f}} \leq 63$ & 91 & 1.004 & 1.004 & 1.004 & 1.004 & 0.965 & 0.965 & 0.965 \\
\hline & $63<\mathrm{t}_{\mathrm{f}} \leq 80$ & 117 & 1.042 & 1.042 & 1.042 & 1.042 & 0.977 & 0.977 & 0.977 \\
\hline & $80<\mathrm{t}_{\mathrm{f}} \leq 100$ & 26 & 1.061 & 1.061 & 1.061 & 1.061 & 0.982 & 0.982 & 0.982 \\
\hline & $\mathrm{t}_{\mathrm{f}}>100$ & 104 & 0.990 & 0.990 & 0.990 & 0.990 & 0.961 & 0.961 & 0.961 \\
\hline \multirow{6}{*}{ S355 } & $0<\mathrm{t}_{\mathrm{f}} \leq 16$ & 91 & 0.995 & 0.995 & 1.044 & 0.995 & 0.998 & 1.002 & 0.998 \\
\hline & $16<\mathrm{t}_{\mathrm{f}} \leq 40$ & 182 & 1.012 & 1.012 & 1.047 & 1.058 & 1.032 & 1.031 & 1.076 \\
\hline & $40<\mathrm{t}_{\mathrm{f}} \leq 63$ & 91 & 0.955 & 0.955 & 1.000 & 0.955 & 0.964 & 0.972 & 0.964 \\
\hline & $63<\mathrm{t}_{\mathrm{f}} \leq 80$ & 117 & 0.977 & 0.977 & 1.034 & 1.020 & 0.971 & 0.985 & 1.012 \\
\hline & $80<\mathrm{t}_{\mathrm{f}} \leq 100$ & 26 & 0.993 & 0.993 & 1.051 & 0.993 & 0.972 & 0.986 & 0.972 \\
\hline & $\mathrm{t}_{\mathrm{f}}>100$ & 104 & 0.961 & 0.961 & 0.981 & 0.961 & 0.966 & 0.968 & 0.966 \\
\hline \multirow{6}{*}{ S460 } & $0<\mathrm{tf}_{\mathrm{f}} \leq 16$ & 91 & 1.137 & 1.060 & 1.305 & 1.137 & 1.041 & 1.071 & 1.041 \\
\hline & $16<\mathrm{tf}_{\mathrm{f}} \leq 40$ & 182 & 1.152 & 1.066 & 1.287 & 1.243 & 1.067 & 1.091 & 1.148 \\
\hline & $40<\mathrm{tf}_{\mathrm{f}} \leq 63$ & 91 & 1.077 & 1.000 & 1.202 & 1.077 & 1.009 & 1.035 & 1.009 \\
\hline & $63<\mathrm{t}_{\mathrm{f}} \leq 80$ & 117 & 1.105 & 1.000 & 1.250 & 1.197 & 1.016 & 1.053 & 1.095 \\
\hline & $80<\mathrm{t}_{\mathrm{f}} \leq 100$ & 26 & 1.121 & 1.035 & 1.278 & 1.121 & 1.021 & 1.063 & 1.021 \\
\hline & $\mathrm{t}_{\mathrm{f}}>100$ & 104 & 1.006 & 1.006 & 1.064 & 1.006 & 1.013 & 1.027 & 1.013 \\
\hline
\end{tabular}




\section{Notations:}

- EN 10025 - minimum yield stress according to EN 10025

- EN 10025 (S460) - minimum yield stress according to EN 10025 and new bucking curves for S460;

- EN $10025 f_{y i}$ - yield stress proportional to $f_{y}$;

- EC3 - minimum yield stress according to EN 10025;

Table B2 All Results for Minor and Major Axis of Hot-rolled Sections, normalized $\gamma_{\mathrm{M} 1}$ with the Average Value for $\mathrm{S} 235 / \mathrm{S} 355 \mathrm{t} \leq 40 \mathrm{~mm}, \mathrm{~h} / \mathrm{b}>1.2$ and Major Axis of Flexural Buckling

(the Values in Green in Table B1)

\begin{tabular}{|c|c|c|c|c|c|c|c|}
\hline \multirow{2}{*}{ Sub-set } & & & \multirow[b]{2}{*}{$\mathbf{n}$} & \multicolumn{2}{|c|}{ Minor axis } & \multicolumn{2}{|c|}{ Major axis } \\
\hline & & & & EN10025 & $\operatorname{EN10025}_{f_{\mathrm{yi}}}$ & EN10025 & $\operatorname{EN10025} \mathbf{f}_{\mathbf{y i}}$ \\
\hline \multirow{12}{*}{ S355 } & \multirow{3}{*}{$\mathrm{h} / \mathrm{b}>1.2 \quad \mathrm{t}_{\mathrm{f}}<40 \mathrm{~mm}$} & Low & 52 & 0.971 & 1.001 & 0.981 & 0.992 \\
\hline & & Medium & 65 & 0.950 & 1.007 & 0.949 & 0.974 \\
\hline & & High & 52 & 0.960 & 0.970 & 0.980 & 0.984 \\
\hline & \multirow{3}{*}{$\begin{array}{c}\mathrm{h} / \mathrm{b}>1.2 \\
\operatorname{tr}(40 ; 100) \mathrm{mm}\end{array}$} & Low & 52 & 0.925 & 0.942 & 0.949 & 0.950 \\
\hline & & Medium & 65 & 0.874 & 0.910 & 0.874 & 0.886 \\
\hline & & High & 52 & 0.917 & 0.922 & 0.942 & 0.946 \\
\hline & \multirow{3}{*}{$\mathrm{h} / \mathrm{b}>1.2 \quad \mathrm{t}_{\mathrm{f}}>100 \mathrm{~mm}$} & Low & 32 & 0.937 & 0.949 & 0.949 & 0.951 \\
\hline & & Medium & 40 & 0.881 & 0.911 & 0.879 & 0.889 \\
\hline & & High & 32 & 0.912 & 0.917 & 0.944 & 0.945 \\
\hline & \multirow{3}{*}{$\mathrm{h} / \mathrm{b} \leq 1.2 \mathrm{t}_{\mathrm{f}}<100 \mathrm{~mm}$} & Low & 52 & 0.975 & 1.011 & 0.958 & 0.964 \\
\hline & & Medium & 65 & 0.940 & 1.022 & 0.906 & 0.943 \\
\hline & & High & 52 & 0.923 & 0.943 & 0.947 & 0.954 \\
\hline \multirow{12}{*}{ S460 } & \multirow{3}{*}{$\mathrm{h} / \mathrm{b}>1.2 \quad \mathrm{t}_{\mathrm{f}}<40 \mathrm{~mm}$} & Low & 52 & 1.123 & 1.204 & 1.054 & 1.080 \\
\hline & & Medium & 65 & 1.147 & 1.271 & 1.022 & 1.074 \\
\hline & & High & 52 & 1.067 & 1.113 & 1.009 & 1.022 \\
\hline & \multirow{3}{*}{$\begin{array}{c}\mathrm{h} / \mathrm{b}>1.2 \\
\mathrm{t}_{\mathrm{f}}(40 ; 100) \mathrm{mm}\end{array}$} & Low & 52 & 1.061 & 1.121 & 1.014 & 1.026 \\
\hline & & Medium & 65 & 1.058 & 1.150 & 0.953 & 0.978 \\
\hline & & High & 52 & 1.012 & 1.047 & 0.983 & 0.987 \\
\hline & \multirow{3}{*}{$\mathrm{h} / \mathrm{b}>1.2 \quad \mathrm{t}_{\mathrm{f}}>100 \mathrm{~mm}$} & Low & 32 & 1.000 & 1.035 & 1.019 & 1.031 \\
\hline & & Medium & 40 & 0.945 & 1.018 & 0.962 & 0.989 \\
\hline & & High & 32 & 0.954 & 0.965 & 0.983 & 0.986 \\
\hline & \multirow{3}{*}{$\mathrm{h} / \mathrm{b} \leq 1.2 \mathrm{t}_{\mathrm{f}}<100 \mathrm{~mm}$} & Low & 52 & 1.116 & 1.241 & 1.033 & 1.062 \\
\hline & & Medium & 65 & 1.126 & 1.312 & 0.987 & 1.067 \\
\hline & & High & 52 & 1.022 & 1.118 & 0.988 & 1.002 \\
\hline
\end{tabular}

\section{Notations:}

- $\quad$ EN 10025 - minimum yield stress according to EN 10025

- $\quad$ EN $10025 f_{y i}$ - yield stress proportional to $f_{y}$; 
Table B3. Normalized Partial Safety Factors, Minor and Major Axis Flexural Buckling, according to Buckling Curves

\begin{tabular}{|c|c|c|c|c|c|c|c|c|c|}
\hline \multirow[b]{2}{*}{ Sub-set } & & & \multicolumn{4}{|c|}{ Minor axis } & \multicolumn{3}{|c|}{ Major axis } \\
\hline & & $\mathbf{n}$ & $\begin{array}{l}\text { Annex } \\
\text { D (fy) }\end{array}$ & $\begin{array}{c}\text { Annex D } \\
(\text { fy+CS) }\end{array}$ & $\begin{array}{c}\text { Annex D } \\
\left(\mathbf{f y}+\mathbf{C S}+\mathbf{E}_{5 \%}\right)\end{array}$ & $\begin{array}{c}\text { Annex D } \\
\left(\mathbf{f y}+\mathbf{C S}+\mathbf{E}_{3} \%\right)\end{array}$ & $\begin{array}{l}\text { Annex } \\
\text { D (fy) }\end{array}$ & $\begin{array}{c}\text { Annex } \\
\text { D } \\
(\mathbf{f y}+\mathbf{C S})\end{array}$ & $\begin{array}{c}\text { Annex D } \\
(\text { fy+CS+E) }\end{array}$ \\
\hline Total & & 1833 & 1.039 & 1.091 & 1.121 & 1.102 & 1.033 & 1.069 & 1.104 \\
\hline Low & & 564 & 1.003 & 1.036 & 1.042 & 1.038 & 0.998 & 1.024 & 1.029 \\
\hline Medium & & 705 & 1.022 & 1.074 & 1.104 & 1.085 & 1.017 & 1.052 & 1.089 \\
\hline High & & 564 & 0.997 & 1.071 & 1.126 & 1.092 & 1.026 & 1.076 & 1.143 \\
\hline S235 & & 611 & 1.032 & 1.089 & 1.123 & 1.102 & 0.995 & 1.033 & 1.071 \\
\hline S355 & & 611 & 0.988 & 1.041 & 1.072 & 1.053 & 0.993 & 1.028 & 1.062 \\
\hline S460 & & 611 & 1.033 & 1.090 & 1.122 & 1.102 & 1.034 & 1.077 & 1.120 \\
\hline \multirow{3}{*}{ S235 } & Low & 188 & 0.983 & 1.017 & 1.025 & 1.020 & 0.951 & 0.976 & 0.983 \\
\hline & Medium & 235 & 1.025 & 1.083 & 1.118 & 1.096 & 0.980 & 1.018 & 1.058 \\
\hline & High & 188 & 0.996 & 1.080 & 1.139 & 1.103 & 0.996 & 1.050 & 1.120 \\
\hline \multirow{3}{*}{ S355 } & Low & 188 & 0.960 & 0.995 & 1.002 & 0.997 & 0.966 & 0.992 & 0.998 \\
\hline & Medium & 235 & 0.944 & 1.001 & 1.034 & 1.013 & 0.948 & 0.984 & 1.021 \\
\hline & High & 188 & 0.957 & 1.033 & 1.088 & 1.055 & 0.983 & 1.032 & 1.097 \\
\hline \multirow{3}{*}{ S460 } & Low & 188 & 1.019 & 1.054 & 1.059 & 1.055 & 1.030 & 1.058 & 1.062 \\
\hline & Medium & 235 & 0.998 & 1.056 & 1.091 & 1.070 & 1.012 & 1.055 & 1.101 \\
\hline & High & 188 & 0.980 & 1.062 & 1.122 & 1.086 & 1.014 & 1.078 & 1.158 \\
\hline \multirow{4}{*}{ S235 } & $\mathrm{h} / \mathrm{b}>1.2 \quad \mathrm{t}_{\mathrm{f}}<40 \mathrm{~mm}$ & 169 & 1.033 & 1.108 & 1.151 & 1.125 & 1.005 & 1.062 & 1.113 \\
\hline & $\mathrm{h} / \mathrm{b}>1.2 \quad \mathrm{t}_{\mathrm{f}}(40 ; 100) \mathrm{mm}$ & 169 & 0.953 & 1.021 & 1.060 & 1.037 & 0.951 & 0.992 & 1.033 \\
\hline & $\mathrm{h} / \mathrm{b}>1.2 \quad \mathrm{t}_{\mathrm{f}}>100 \mathrm{~mm}$ & 104 & 0.990 & 1.052 & 1.089 & 1.066 & 0.961 & 1.000 & 1.043 \\
\hline & $\mathrm{h} / \mathrm{b} \leq 1.2 \mathrm{t}_{\mathrm{f}}<100 \mathrm{~mm}$ & 169 & 1.074 & 1.143 & 1.181 & 1.157 & 0.985 & 1.035 & 1.080 \\
\hline \multirow{4}{*}{ S355 } & $\mathrm{h} / \mathrm{b}>1.2 \quad \mathrm{t}_{\mathrm{f}}<40 \mathrm{~mm}$ & 169 & 0.988 & 1.061 & 1.101 & 1.077 & 0.995 & 1.047 & 1.094 \\
\hline & $\mathrm{h} / \mathrm{b}>1.2 \quad \operatorname{tr}(40 ; 100) \mathrm{mm}$ & 169 & 0.940 & 0.997 & 1.032 & 1.011 & 0.962 & 0.997 & 1.032 \\
\hline & $\mathrm{h} / \mathrm{b}>1.2 \quad \mathrm{t} \mathrm{f}>100 \mathrm{~mm}$ & 104 & 0.961 & 1.017 & 1.049 & 1.029 & 0.966 & 0.999 & 1.036 \\
\hline & $\mathrm{h} / \mathrm{b} \leq 1.2 \mathrm{t}_{\mathrm{f}}<100 \mathrm{~mm}$ & 169 & 1.011 & 1.073 & 1.107 & 1.086 & 0.980 & 1.023 & 1.061 \\
\hline \multirow{4}{*}{ S460 } & $\mathrm{h} / \mathrm{b}>1.2 \quad \mathrm{t}_{\mathrm{f}}<40 \mathrm{~mm}$ & 169 & 1.049 & 1.117 & 1.156 & 1.132 & 1.041 & 1.104 & 1.156 \\
\hline & $\mathrm{h} / \mathrm{b}>1.2 \quad \mathrm{t}_{\mathrm{f}}(40 ; 100) \mathrm{mm}$ & 169 & 0.987 & 1.047 & 1.083 & 1.061 & 1.006 & 1.052 & 1.096 \\
\hline & $\mathrm{h} / \mathrm{b}>1.2 \quad \mathrm{t} f>100 \mathrm{~mm}$ & 104 & 1.006 & 1.069 & 1.106 & 1.084 & 1.013 & 1.055 & 1.101 \\
\hline & $\mathrm{h} / \mathrm{b} \leq 1.2 \mathrm{t}_{\mathrm{f}}<100 \mathrm{~mm}$ & 169 & 1.052 & 1.114 & 1.147 & 1.126 & 1.032 & 1.084 & 1.130 \\
\hline
\end{tabular}


Table B4. Normalized Partial Safety Factors, Minor Axis Flexural Buckling, according to Buckling Curves and Slenderness

\begin{tabular}{|c|c|c|c|c|c|c|c|c|c|c|}
\hline \multirow{3}{*}{ 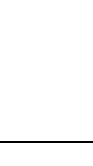 } & \multirow{2}{*}{ Sub-set } & & \multicolumn{5}{|c|}{ Minor axis } & \multicolumn{3}{|c|}{ Major axis } \\
\hline & & & $\mathbf{n}$ & $\begin{array}{c}\text { Annex D } \\
\text { (fy) }\end{array}$ & $\begin{array}{c}\text { Annex D } \\
(\text { fy+CS) }\end{array}$ & $\begin{array}{c}\text { Annex D } \\
\left(\mathrm{fy}+\mathrm{CS}+\mathrm{E}_{5 \%}\right)\end{array}$ & $\begin{array}{c}\text { Annex D } \\
\left(\text { fy }+ \text { CS }+E_{3} \%\right)\end{array}$ & $\begin{array}{c}\text { Annex } \\
\text { D (fy) }\end{array}$ & $\begin{array}{c}\text { Annex } \\
\text { D } \\
(f y+C S) \\
\end{array}$ & $\begin{array}{c}\text { Annex D } \\
(\text { fy+CS}+E \\
)\end{array}$ \\
\hline & \multirow{3}{*}{$\begin{array}{l}\mathrm{h} / \mathrm{b}>1.2 \\
\mathrm{t}_{\mathrm{f}}<40 \mathrm{~mm}\end{array}$} & Low & 52 & 0.990 & 1.029 & 1.037 & 1.032 & 0.972 & 1.001 & 1.007 \\
\hline \multirow{11}{*}{ S235 } & & Medium & 65 & 1.023 & 1.106 & 1.154 & 1.125 & 0.988 & 1.053 & 1.111 \\
\hline & & High & 52 & 0.991 & 1.118 & 1.191 & 1.147 & 0.993 & 1.087 & 1.175 \\
\hline & \multirow{3}{*}{$\begin{array}{c}\mathrm{h} / \mathrm{b}>1.2 \\
\mathrm{t}_{\mathrm{f}}(40 ; 100) \mathrm{mm}\end{array}$} & Low & 52 & 0.926 & 0.961 & 0.971 & 0.964 & 0.924 & 0.948 & 0.955 \\
\hline & & Medium & 65 & 0.931 & 1.005 & 1.049 & 1.022 & 0.894 & 0.947 & 0.996 \\
\hline & & High & 52 & 0.936 & 1.043 & 1.108 & 1.069 & 0.949 & 1.017 & 1.092 \\
\hline & \multirow{3}{*}{$\begin{array}{c}\mathrm{h} / \mathrm{b}>1.2 \\
\mathrm{tf}>100 \mathrm{~mm}\end{array}$} & Low & 32 & 0.944 & 0.982 & 0.992 & 0.986 & 0.933 & 0.957 & 0.965 \\
\hline & & Medium & 40 & 0.950 & 1.022 & 1.063 & 1.038 & 0.909 & 0.958 & 1.010 \\
\hline & & High & 32 & 0.940 & 1.041 & 1.105 & 1.067 & 0.952 & 1.014 & 1.093 \\
\hline & \multirow{3}{*}{$\begin{array}{c}\mathrm{h} / \mathrm{b} \leq 1.2 \\
\mathrm{t}_{\mathrm{f}}<100 \mathrm{~mm}\end{array}$} & Low & 52 & 1.011 & 1.058 & 1.068 & 1.061 & 0.949 & 0.982 & 0.990 \\
\hline & & Medium & 65 & 1.049 & 1.126 & 1.170 & 1.143 & 0.964 & 1.019 & 1.070 \\
\hline & & High & 52 & 0.985 & 1.101 & 1.169 & 1.128 & 0.970 & 1.046 & 1.125 \\
\hline \multirow{12}{*}{ S355 } & \multirow{3}{*}{$\begin{array}{c}\mathrm{h} / \mathrm{b}>1.2 \\
\mathrm{t}_{\mathrm{f}}<40 \mathrm{~mm}\end{array}$} & Low & 52 & 0.971 & 1.010 & 1.018 & 1.013 & 0.981 & 1.012 & 1.017 \\
\hline & & Medium & 65 & 0.950 & 1.034 & 1.079 & 1.052 & 0.949 & 1.015 & 1.070 \\
\hline & & High & 52 & 0.960 & 1.074 & 1.144 & 1.102 & 0.980 & 1.064 & 1.149 \\
\hline & \multirow{3}{*}{$\begin{array}{c}\mathrm{h} / \mathrm{b}>1.2 \\
\mathrm{t}_{\mathrm{f}}(40 ; 100) \mathrm{mm}\end{array}$} & Low & 52 & 0.925 & 0.959 & 0.967 & 0.962 & 0.949 & 0.972 & 0.978 \\
\hline & & Medium & 65 & 0.874 & 0.946 & 0.987 & 0.962 & 0.874 & 0.922 & 0.967 \\
\hline & & High & 52 & 0.917 & 1.007 & 1.067 & 1.031 & 0.942 & 1.001 & 1.072 \\
\hline & \multirow{3}{*}{$\begin{array}{c}\mathrm{h} / \mathrm{b}>1.2 \\
\mathrm{t}_{\mathrm{f}}>100 \mathrm{~mm}\end{array}$} & Low & 32 & 0.937 & 0.973 & 0.982 & 0.976 & 0.949 & 0.974 & 0.980 \\
\hline & & Medium & 40 & 0.881 & 0.952 & 0.991 & 0.967 & 0.879 & 0.925 & 0.972 \\
\hline & & High & 32 & 0.912 & 1.001 & 1.060 & 1.024 & 0.944 & 0.997 & 1.070 \\
\hline & \multirow{3}{*}{$\begin{array}{c}\mathrm{h} / \mathrm{b} \leq 1.2 \\
\mathrm{t}_{\mathrm{f}}<100 \mathrm{~mm}\end{array}$} & Low & 52 & 0.975 & 1.020 & 1.029 & 1.023 & 0.958 & 0.991 & 0.998 \\
\hline & & Medium & 65 & 0.940 & 1.014 & 1.053 & 1.029 & 0.906 & 0.961 & 1.009 \\
\hline & & High & 52 & 0.923 & 1.023 & 1.085 & 1.048 & 0.947 & 1.012 & 1.085 \\
\hline \multirow{12}{*}{ S460 } & \multirow{3}{*}{$\begin{array}{c}\mathrm{h} / \mathrm{b}>1.2 \\
\mathrm{t}_{\mathrm{f}}<40 \mathrm{~mm}\end{array}$} & Low & 52 & 1.041 & 1.079 & 1.083 & 1.080 & 1.054 & 1.084 & 1.087 \\
\hline & & Medium & 65 & 1.017 & 1.092 & 1.136 & 1.109 & 1.022 & 1.092 & 1.152 \\
\hline & & High & 52 & 0.982 & 1.080 & 1.149 & 1.107 & 1.009 & 1.109 & 1.202 \\
\hline & \multirow{3}{*}{$\begin{array}{c}\mathrm{h} / \mathrm{b}>1.2 \\
\mathrm{t}_{\mathrm{f}}(40 ; 100) \mathrm{mm}\end{array}$} & Low & 52 & 0.984 & 1.017 & 1.024 & 1.020 & 1.014 & 1.040 & 1.044 \\
\hline & & Medium & 65 & 0.934 & 1.004 & 1.045 & 1.020 & 0.953 & 1.011 & 1.063 \\
\hline & & High & 52 & 0.952 & 1.039 & 1.101 & 1.064 & 0.983 & 1.060 & 1.144 \\
\hline & \multirow{3}{*}{$\begin{array}{c}\mathrm{h} / \mathrm{b}>1.2 \\
\mathrm{t}_{\mathrm{f}}>100 \mathrm{~mm}\end{array}$} & Low & 32 & 1.000 & 1.037 & 1.043 & 1.039 & 1.019 & 1.045 & 1.050 \\
\hline & & Medium & 40 & 0.945 & 1.021 & 1.063 & 1.037 & 0.962 & 1.013 & 1.067 \\
\hline & & High & 32 & 0.954 & 1.057 & 1.124 & 1.084 & 0.983 & 1.054 & 1.140 \\
\hline & \multirow{3}{*}{$\begin{array}{c}\mathrm{h} / \mathrm{b} \leq 1.2 \\
\mathrm{t}_{\mathrm{f}}<100 \mathrm{~mm}\end{array}$} & Low & 52 & 1.028 & 1.072 & 1.079 & 1.075 & 1.033 & 1.068 & 1.073 \\
\hline & & Medium & 65 & 0.979 & 1.050 & 1.090 & 1.065 & 0.987 & 1.048 & 1.102 \\
\hline & & High & 52 & 0.944 & 1.037 & 1.099 & 1.062 & 0.988 & 1.070 & 1.155 \\
\hline
\end{tabular}


Table B5. Partial Safety Factors, Minor Axis Flexural Buckling, according to Buckling Curves

\begin{tabular}{|c|c|c|c|c|c|c|c|c|}
\hline \multirow[b]{2}{*}{ Sub-set } & & & \multicolumn{3}{|c|}{ Minor axis } & \multicolumn{3}{|c|}{ Major axis } \\
\hline & & $\mathbf{n}$ & $\begin{array}{l}\text { Annex } \\
\text { D (fy) }\end{array}$ & $\begin{array}{c}\text { Annex } \\
\text { D } \\
(\mathbf{f y}+\mathrm{CS})\end{array}$ & $\begin{array}{c}\text { Annex D } \\
(\text { fy+CS+E) }\end{array}$ & $\begin{array}{l}\text { Annex } \\
\text { D (fy) }\end{array}$ & $\begin{array}{c}\text { Annex } \\
\text { D } \\
\text { (fy+CS) }\end{array}$ & $\begin{array}{c}\text { Annex D } \\
(\text { fy }+ \text { CS }+E)\end{array}$ \\
\hline \multirow{4}{*}{ S235 } & $\begin{array}{c}\mathrm{h} / \mathrm{b}>1.2 \quad \mathrm{t}_{\mathrm{f}}<40 \mathrm{~mm} \\
\mathrm{~h} / \mathrm{b}>1.2\end{array}$ & 169 & 1.012 & 1.085 & 1.127 & 0.984 & 1.040 & 1.090 \\
\hline & $\mathrm{t} \mathrm{f}(40 ; 100) \mathrm{mm}$ & 169 & 0.934 & 1.000 & 1.039 & 0.932 & 0.972 & 1.012 \\
\hline & $\mathrm{h} / \mathrm{b}>1.2 \quad \mathrm{t}_{\mathrm{f}}>100 \mathrm{~mm}$ & 104 & 0.969 & 1.031 & 1.067 & 0.942 & 0.979 & 1.022 \\
\hline & $\mathrm{h} / \mathrm{b} \leq 1.2 \mathrm{t}_{\mathrm{f}}<100 \mathrm{~mm}$ & 169 & 1.052 & 1.119 & 1.157 & 0.965 & 1.014 & 1.058 \\
\hline \multirow{4}{*}{ S355 } & $\begin{array}{c}\mathrm{h} / \mathrm{b}>1.2 \quad \mathrm{t}_{\mathrm{f}}<40 \mathrm{~mm} \\
\mathrm{~h} / \mathrm{b}>1.2\end{array}$ & 169 & 0.968 & 1.039 & 1.079 & 0.975 & 1.026 & 1.072 \\
\hline & $\mathrm{t}_{\mathrm{f}}(40 ; 100) \mathrm{mm}$ & 169 & 0.920 & 0.977 & 1.011 & 0.942 & 0.976 & 1.011 \\
\hline & $\mathrm{h} / \mathrm{b}>1.2 \quad \mathrm{t}_{\mathrm{f}}>100 \mathrm{~mm}$ & 104 & 0.941 & 0.996 & 1.028 & 0.946 & 0.978 & 1.015 \\
\hline & $\mathrm{h} / \mathrm{b} \leq 1.2 \mathrm{t}_{\mathrm{f}}<100 \mathrm{~mm}$ & 169 & 0.990 & 1.051 & 1.084 & 0.960 & 1.002 & 1.040 \\
\hline \multirow{4}{*}{ S460 } & $\begin{array}{c}\mathrm{h} / \mathrm{b}>1.2 \quad \mathrm{t}_{\mathrm{f}}<40 \mathrm{~mm} \\
\mathrm{~h} / \mathrm{b}>1.2\end{array}$ & 169 & 1.028 & 1.094 & 1.133 & 1.020 & 1.081 & 1.132 \\
\hline & $\mathrm{t}_{\mathrm{f}}(40 ; 100) \mathrm{mm}$ & 169 & 0.967 & 1.025 & 1.060 & 0.985 & 1.030 & 1.074 \\
\hline & $\mathrm{h} / \mathrm{b}>1.2 \quad \mathrm{t}_{\mathrm{f}}>100 \mathrm{~mm}$ & 104 & 0.985 & 1.047 & 1.084 & 0.992 & 1.034 & 1.078 \\
\hline & $\mathrm{h} / \mathrm{b} \leq 1.2 \mathrm{t}_{\mathrm{f}}<100 \mathrm{~mm}$ & 169 & 1.030 & 1.091 & 1.124 & 1.011 & 1.062 & 1.107 \\
\hline
\end{tabular}

Table B6. Partial Safety Factors, Minor Axis Flexural Buckling, according to Buckling Curves and Slenderness, c.o.v. of Modulus of Elasticity 5\%

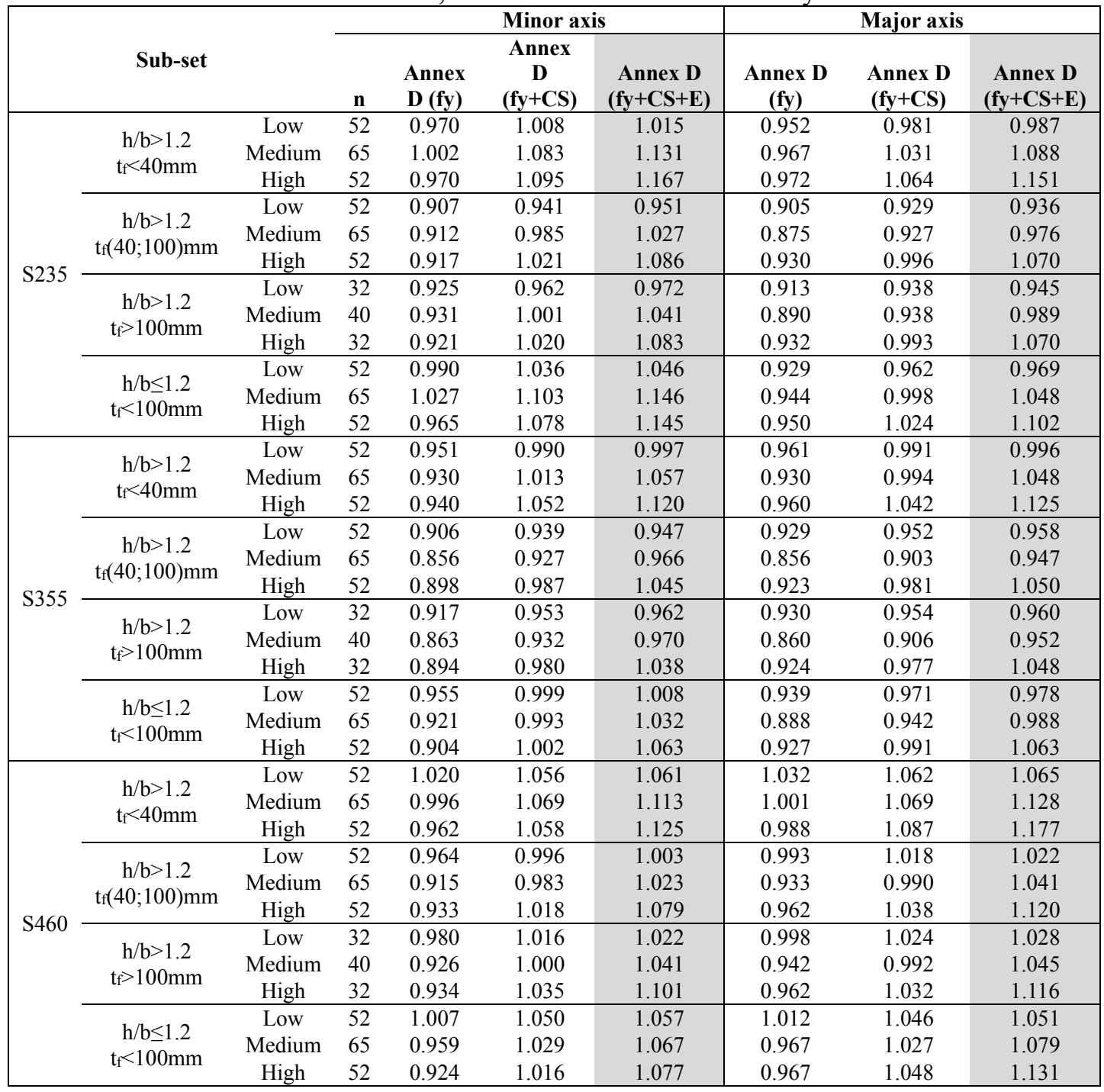

